\title{
فاعلية استخدام التعليم المتمايز في تنمية بعض مهارات التعلم المنظم ذاتيًا لدي طلاب المر حلة الثانوية
}

\author{
إعداد \\ أ.م.د / عبدالله ابراهيه يوسف \\ أستاذ المناهج وطرق تلريس المواد الفلسفية \\ المساعد بكلية الثربية - جامعة الفيوم \\ aiy00@fayoum.edu.eg \\ أ/ سعيلة عبلالستار حافظظ يوسف \\ معيدة بقسم المناهج وطرق تلدريس المواد \\ الفلسفية بكلبة التربية بقنا- جامعة جنوب الو ادي \\ Saidaabdelsttar373@gmail.com \\ أ. أد / حسين محمد أحمد عبدالباسط \\ أستاذ المناهج وطرق تدريس الدراسات الإجتماعية \\ كلية التربية بقنا - جامعة جنوب الو ادي لادي \\ hussainbaset@svu.edu.eg

\section{1/ محمد أحمد عبلدالرحمن} \\ مدرس المناهج وطرق تدريس الار اسات الإجتماعية \\ كلية التربية بقنا - جامعة جنوب الو ادي \\ Moedu2011@yhoo.com
}




\section{فاعلية استخدام التعليم المتثمايز في تثمية بعض مهارات التعلم المنظم

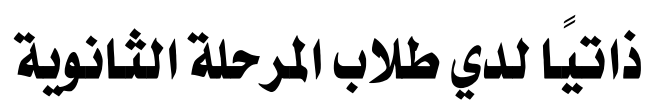

إعداد

\section{أ.م.د/ عبدالله ابراهيه يوسفف}

أستاذ المناهج وطرق تدريس المواد الفلسفية

المساعد بكلية النربية - جامعة الفيوم

aiy00@fayoum.edu.eg

\section{أ/ سعيدة عبلالستار حافظ يوسف}

معبدة بقسم المناهج وطرق تلريس المو اد

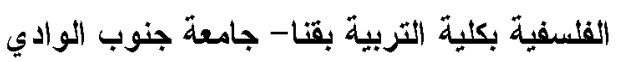

Saidaabdelsttar373@gmail.com
أ.د / حسيز محمد أحمد عبدالباسط أستاذ المناهج وطرق تدريس اللارسات الإجتماعية

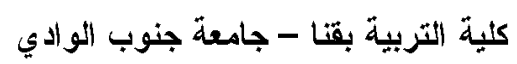
hussainbaset@svu.edu.eg

\section{د محمد أحمد عبلدالرحمن}

مدرس المناهج وطرق تلريس الار اسات الإجتماعية كلية التربية بقنا - جامعة جنوب الو الدي

Moedu2011@yhoo.com

المستخلص : - (الم :

هدف البحث إلي التعرف علي فاعلية استخدام التعليم المتمايز في تنمية بعض مهار ات

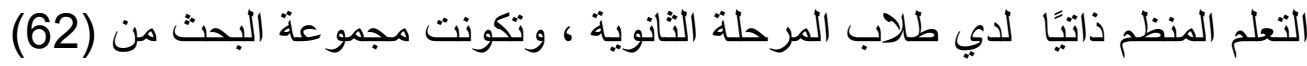

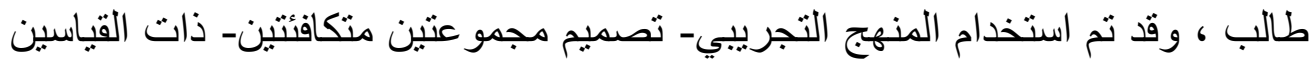

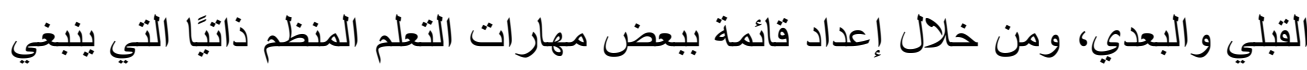

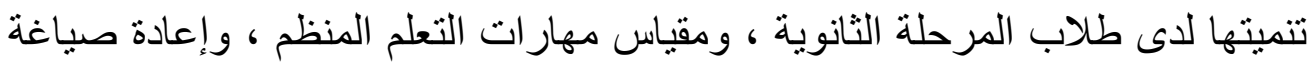

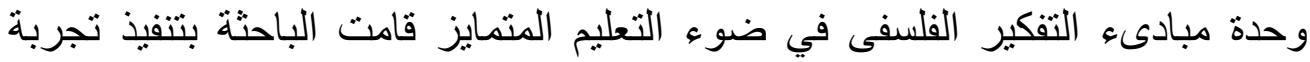

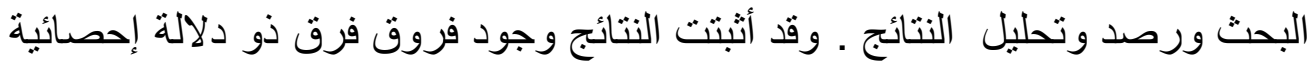
بين متوسطي درجات طلاب المجموعة التجريبية والمجموعة الضابطة في التطبيق

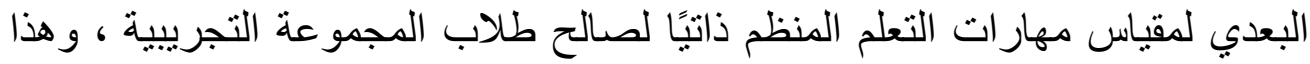

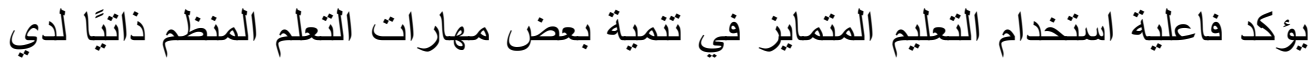

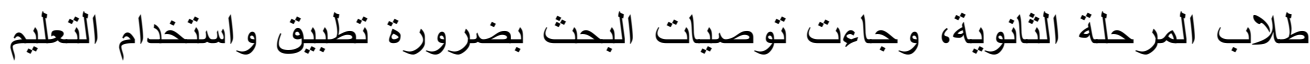
المتمايز في جميع المر احل التعليمية.

الكلمات المفتاحية: التعليم المتمايز - مهار ات التعلم المنظم ذاتيًا. . 


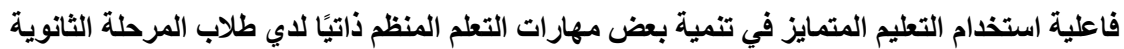

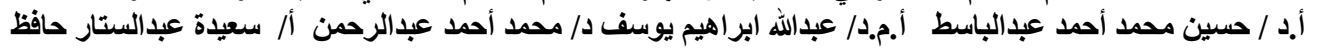

\title{
Effectiveness of Using Differentiated - Instruction in Developing Some Self -Regulated Learning Skills of Secondary School Students
}

\author{
Prof. Dr. Hussein Mohammed Ahmed Abdel-Baset Dr. Abdullah Ibrahim Yousief \\ Professor of curricula and teaching \\ Methods of Social studies \\ Faculty of Education, Qena \\ South Valley University \\ hussainbaset@svu.edu.eg \\ Assistant Professor of curricula and \\ teaching methods of philosophy and sociology \\ Faculty of Education \\ Fayoum University \\ aiy00@ fayoum.edu.eg
}

Dr. Mohammed Ahmed Abdel-Rahman

Lecturer of curricula and teaching

Methods of Social studies

Faculty of Education, Qena

South Valley University

Moedu2011@yhoo.com

Saida Abd-Elsttar Hafez Youssef

Lecturer Assistant -Faculty of Education, Qena In Fulfillment of the Requirements for the Degree Master Major: Curricula \& Methods of Teaching

(philosophy and sociology)

Saidaabdelsttar373@gmail.com

\section{Abstract:}

This Study aimed to identify Effectiveness of Using Differentiated Instruction in Developing Some Self -Regulated Learning Skills of Secondary School Students. The research group consisted of (62) Students. The study used one of the true experimental designs, namely, the pretest- posttest Equivalent- Group design. And prepared a list of Self -Regulated Learning Skills that should be developed of Secondary School Students of using Differentiated -Instruction in view of the list self -Regulated Learning Skills. The research tool was constructed, a preventive Self -Regulated Learning Skills. The results indicated there is a statistically significant difference between the mean scores of the experimental and control groups in the post- administration of the preventive Self -Regulated Learning Skills in favor of the experimental group. This assured Effectiveness of Using Differentiated Instruction in Developing Some Self -Regulated Learning Skills of Secondary School Students. The Study recommended the necessity of applying the Differentiated -Instruction in all educational stages.

Keywords: Differentiated - Instruction / Self -Regulated Learning Skills.

العدد الثاني والأربعون




\section{مقدمة}

شهدت السنوات الماضية تطورات سريعة في جميع مجالات الحياة و لاسيما المجال

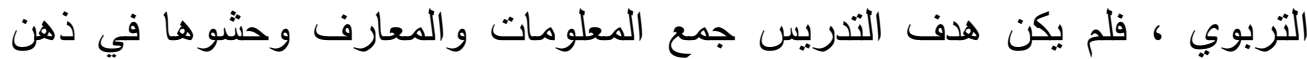

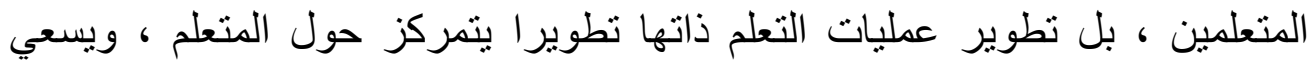
لإطلاق طاقاته ومهار اته وقدر اته و ومعار فئ.

ويعد تدريس مادة الفلسفة مهما في المرحلة الثانوية، لأنه يعمل علي تكوين نظرة

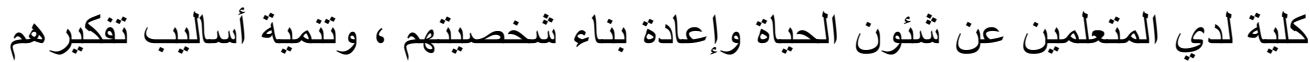

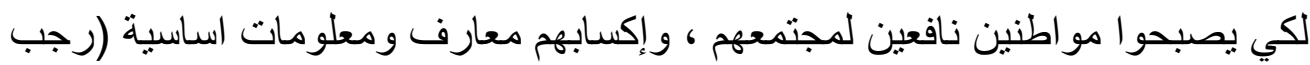

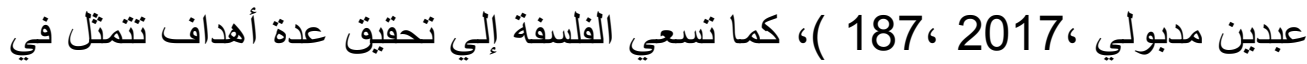

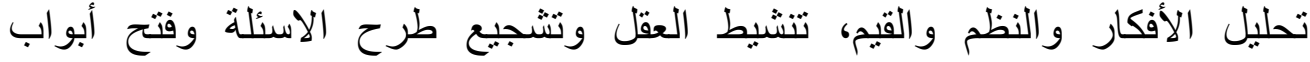

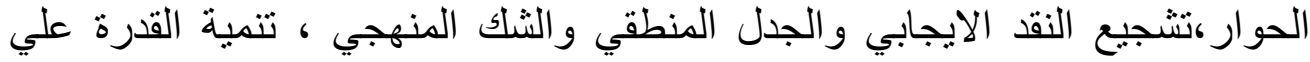

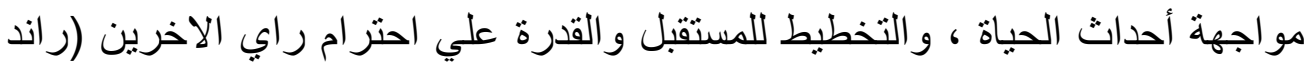

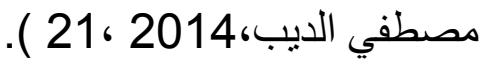

و يتوقف تعلم الفلسفة علي العديد من العوامل ومنها المتعلم ذاته ونشاطاته أثناء

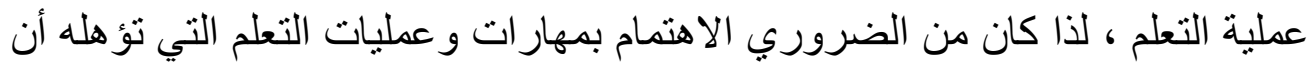

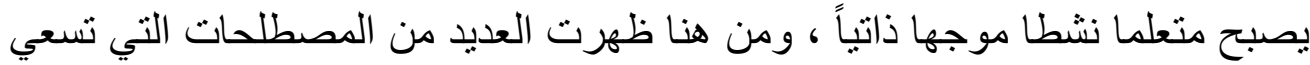
إلي تحقيق ذلك ، و ونها ما يسمي بالتعلم المنظم ذاتياً أو التنظيم الذاتي للتعلم (وليد خليفة

. ( 829 ، 2010،

ويركز التعلم المنظم ذاتياً Self -Regulated Learning علي الطريقة التي يستطيع من خلالها المتعلم أن بنشط ذاتياً، كما أنه يشجع المتعلمين علي تحمل مسئولية

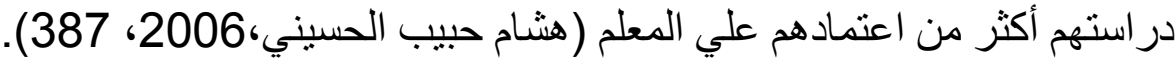

وترجع اهمية التعلم المنظم ذاتياً Self -Regulated Learning إلي أنه يكسب التب المتعلمين القدرة علي التخطيط و التحكم المعرفي والانفعالي و التأمل في مخرجات أدائهم

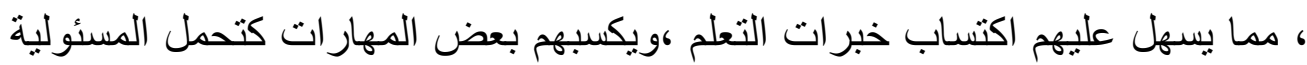

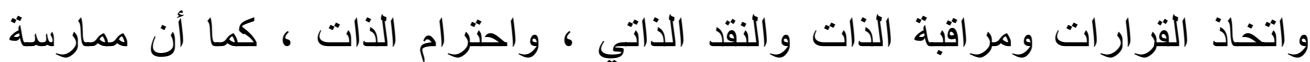

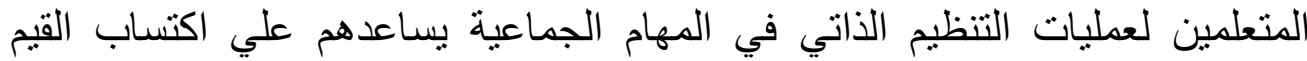

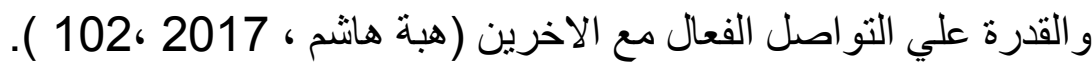


وللتعلم المنظم ذاتياً نأثير ا واضحا في شخصية المتعلم وتطوير أدائه ، ويساعده في اكتساب مهار ات اتخاذ القرار وحل المشكلات مما يؤثر في حياته اليومية و العملية أثناء

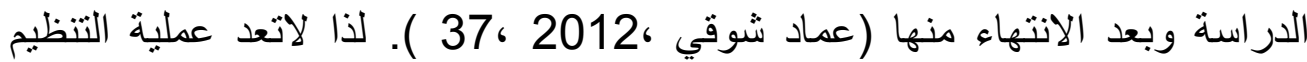

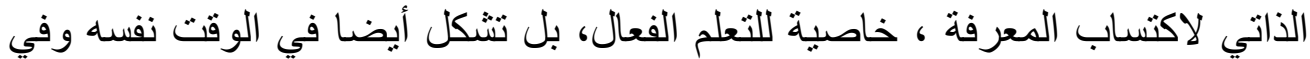

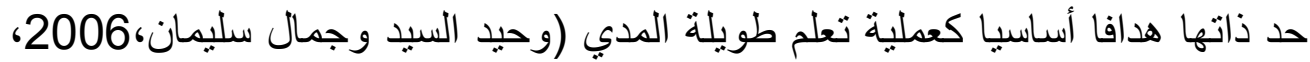

كما أصبح التعلم المنظم ذاتياً البنية المركزية في التفسيرات الحديثة للتعلم الفعال،

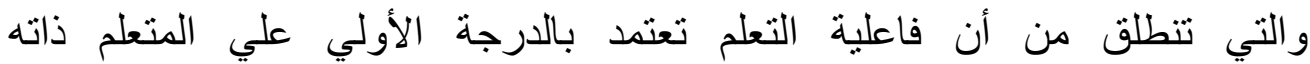

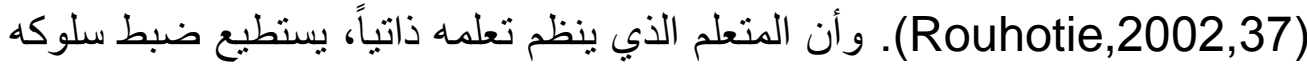

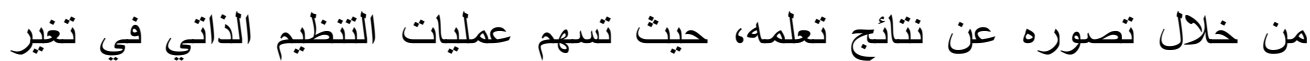
سلوكه(Bandura ,2002, 296).و أنه تعلم ناتج من تعديل سلوكه و وأفكاره الذاتية، لتحقيق الأهداف التعليمية الخاصة به (Schunk , 2001, 125 ).

ويحتاج تنظيم التعلم ذاتياً من خلال تدريس الفلسفة إلي استراتيجيات غير تقليدية ، تر اعي التمايز بين المتعلمين وميولهم واهتماماتهم باعتبار أنهم محور العملية التعليمية كويعد التعليم المتمايز من الاستر اتيجيات الحديثة التي أثنتت فعاليتها في عملية التدريس التئس

$$
\text { في مناهج مختلفة . }
$$

وقد بدأت فكرة التعليم المتمايز تزدهر، حينما تم إعلان وثيقة حقوق الطفل التي أوصت بالتدريس المتمايز للجميع ، باستخدام أساليب مختلفة للمتعلمين تناسب إسب

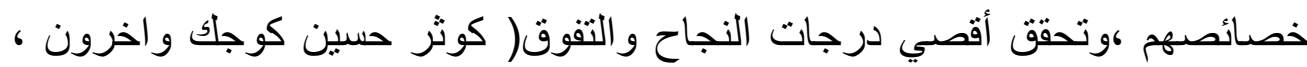
2008 ،12 )، ويهدف التعليم المتمايز إلي رفع مستوي المتعلمين، ليس الذين

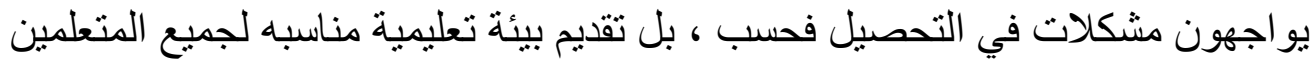
باستخدام أساليب متنوعة المهام (ذوقان عبيدات، وسهيلة ابو السميد، 2007 ، 2007 ، 117 ).

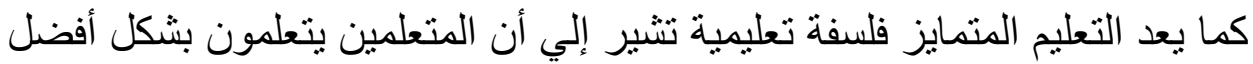

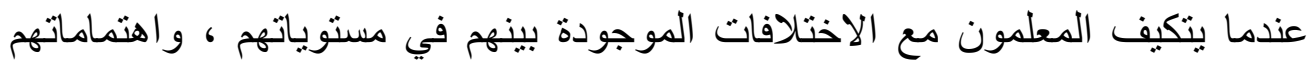

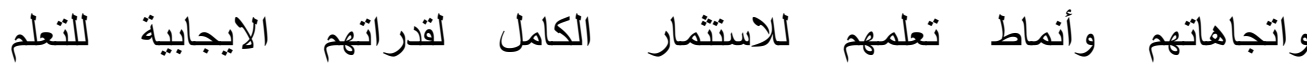
. (Tomlinson,2005)

ونظرًا لأهمية استخدام استراتيجيات متنوعة في العملية التعليمية ، لتنوع وتمايز المتعلمين في ميولهم واهتماماتهم ، فأن الدراسة الحالية تسعي إلي التعرف فلئ فلي فاعلية 
استخدام التعليم المتمايز في تدريس الفلسفة لتنمية بعض مهار ات التعلم المنظم ذاتياً لدي طلاب المرحلة الثانوية.

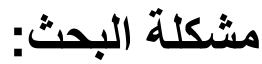

من خلال البحث و الاطلاع لاحظت الباحثة وجود العديد من الدراسات التي أشارت

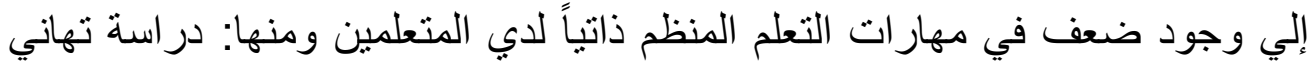
بنت عبدالرحمن بن علي المزيني (2015). التي توصلت إلي أن استخدام أساليب

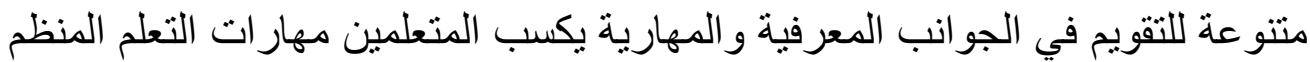

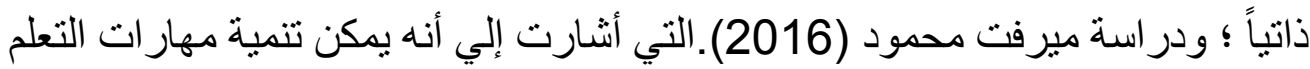

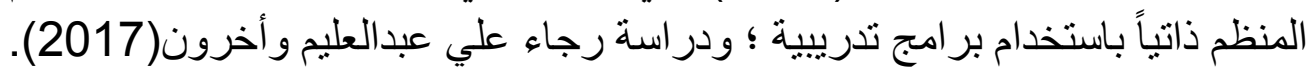

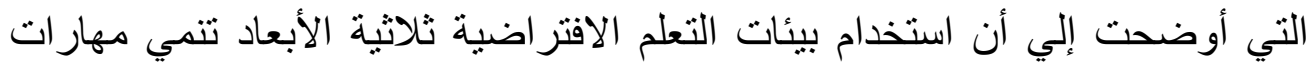

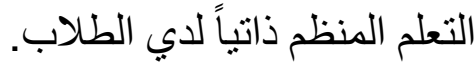

و أوصت بعض الدر اسات بضرورة تنمية مهار ات التعلم المنظم ذاتياً كدر اسة كلا من

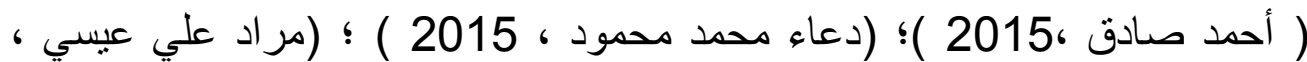

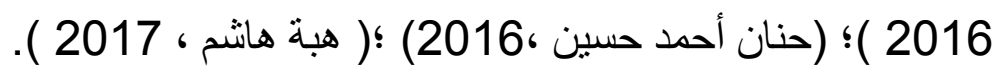
وللتأكد أكثر من المشكلة تم القيام بدر اسة استطلاعية تمثلت في:

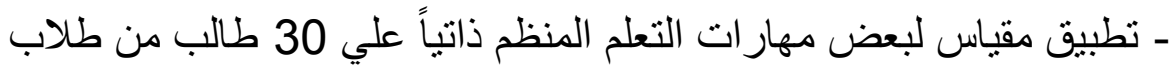

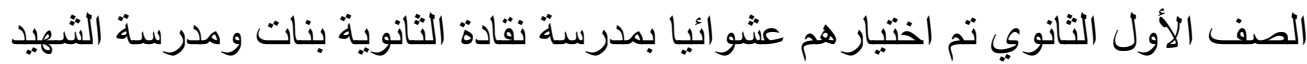

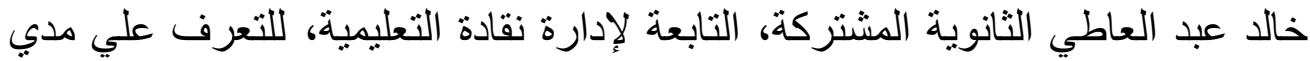

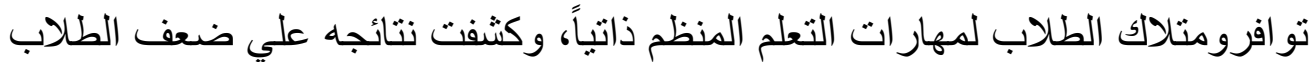
في تو افر مهار ات التعلم المنظم ذاتيًا لديهم ونسبة امتلاكهم لهذه المهار ات (28 \% - إجر اء مقابلة مع خمسة معلمين وخمسة طلاب و وذلك بسؤالهم عن الطرق

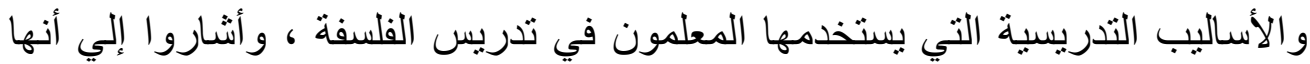

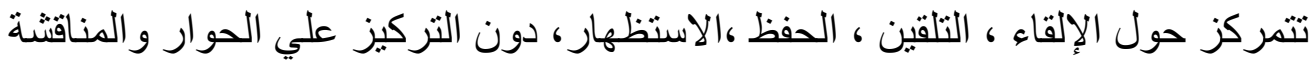

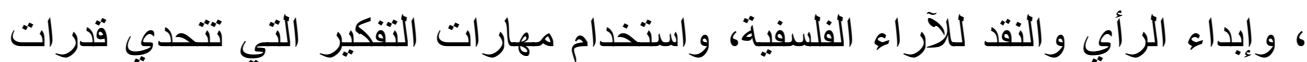

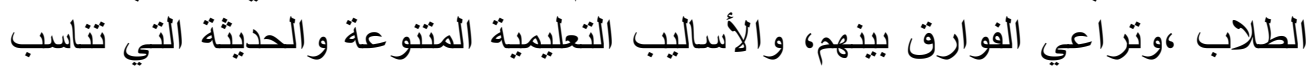

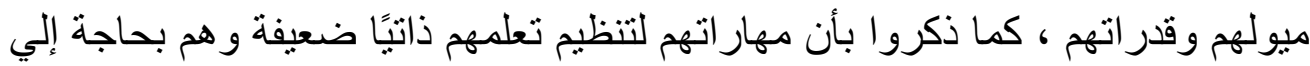
إكتساب بعض الخطو ات التي تساعدهم علي كيفية تنظيم تعلمهم ذاتيًا . 
مما سبق يتضح أن الضعف في بعض مهار ات التعلم المنظم ذاتياً يرجع إلي الطرق

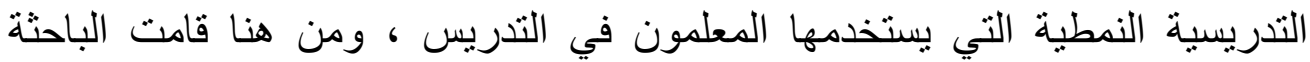

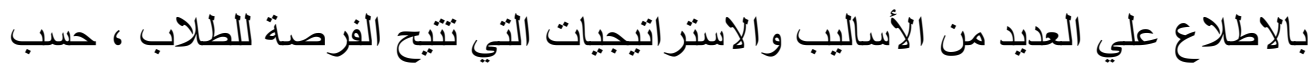

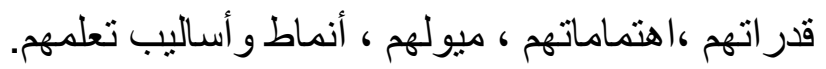

ويعد التعليم المتمايز أحد الاتجاهات الحديثة القادرة علي مراعاة التمايز والفروق

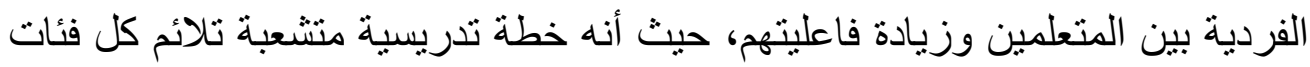

المتعلمين.

ونظرًا لأهمية التعليم المتمايز في العملية التعليمية، قد ركزت العديد من البحوث

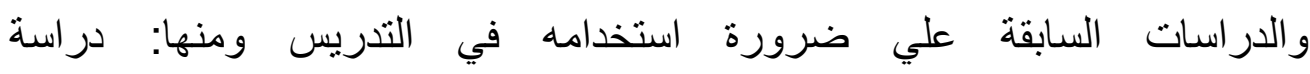

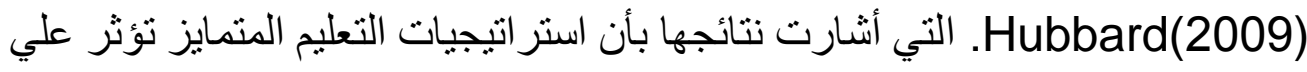

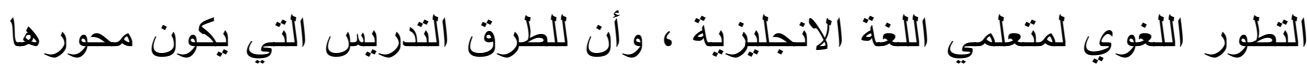

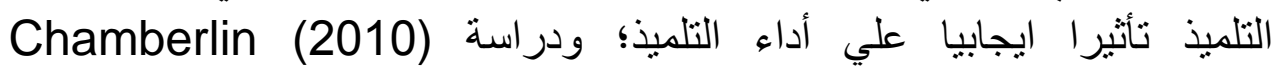
\&Powers

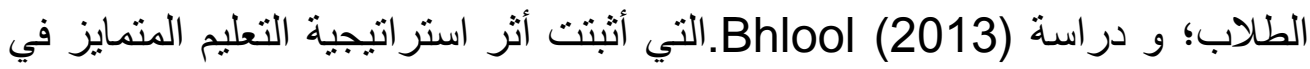

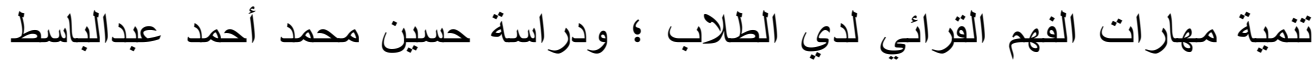

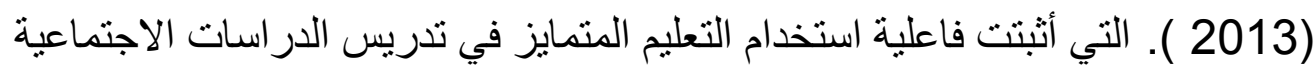

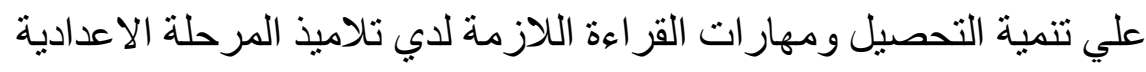

كما توصلت دراسة شريهان محمد صديق (2017 ). إلي فاعلية التعليم المتمايز في

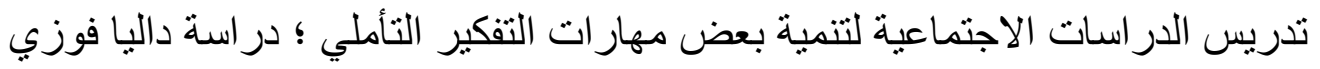

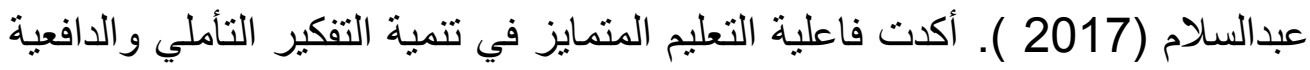

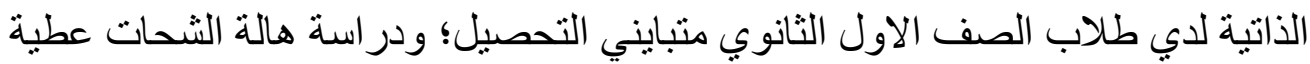
(2017 ).التي أثتتت فاعلية استراتيجيات التعليم المتمايز في تنمية المفاهيم التاريخية

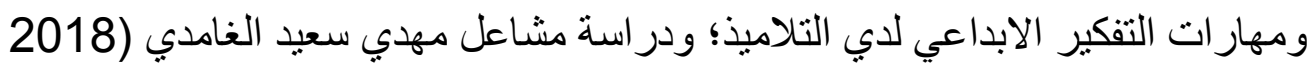

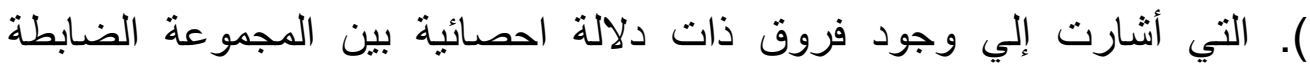

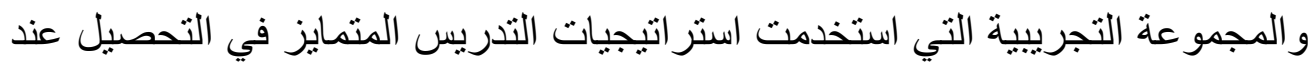

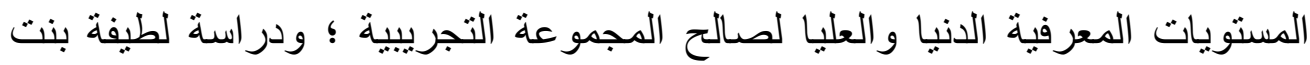
سراج بن علي (2018 ). التي أثنتت أثر استراتيجية التعليم المتمايز في تنمية التفكير التأملي و التحصيل لدي الطالبات . 
من هنا تتحدد مشكلة البحث في وجود ضعف في بعض مهار ات التعلم المنظم ذاتياً،

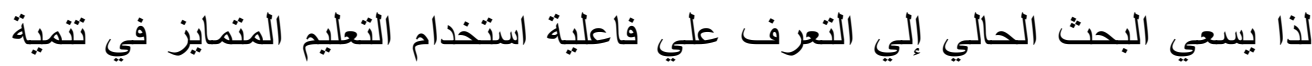

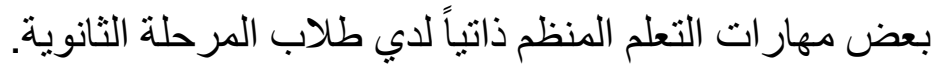
اسئلة البحث : 20 حاول البحث الاجابة عن الاسئلة التالية:-

ا ـ ما مهار ات التعلم المنظم ذاتيا اللازم تو افر ها لدي طلاب الصف الأول الثانوي ؟

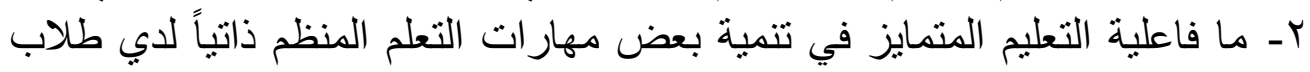

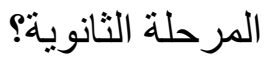

سعي البحث إلي تحقيق الاهداف التالية :-

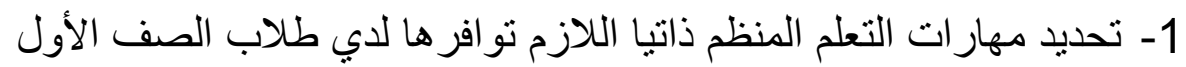

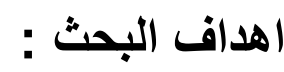
الثانوي. 2- التعرف علي فاعلية استخدام التعليم المتمايز في تنمية بعض مهارات التعلم المنظم ذاتياً لدي طلاب المرحلة الثانوية. فروض البحث : (1) يوجد فرق ذي دلالة إحصائية بين متوسطي درجات طلاب المجموعة التجريبية و المجمو عة الضابطة في التطبيق البعدي لمقياس مهار ات التعلم المنظم ذات ذاتيًا لصالح طلاب المجمو عة التجريبية. r يوجد فرق ذي دلالة إحصائية بين منوسطي درجات طلاب المجمو عة التجريبية في

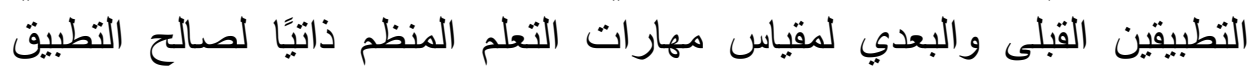

$$
\text { البزّم البحث بالمحددات الحالية : البعدى. }
$$

مجموعة من طلاب الصف الأول الثانوي نظرًا لأنهم بمثلوا النقطة الأولي في تعليم الفلسفة بمفاهيمها المختلفة. 


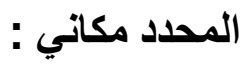

مدرسة نقادة الثانوية بنات ، مدرسة الثهيد خالد عبد العاطي الثانوية المشتركة

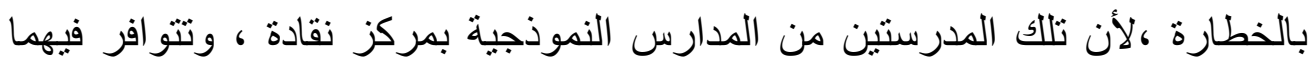

$$
\text { إمكانيات الدر اسة ـ الان }
$$

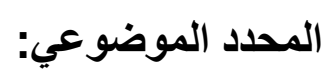

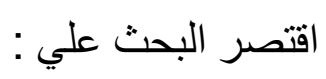

- - تنمية بعض مهار ات التعلم المنظم ذاتياً المناسبة لطلاب المرحلة الثانوية .

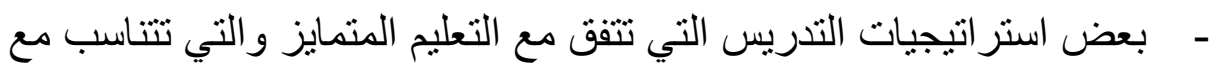

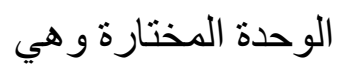

استراتيجيات تدريسية خاصة بالمتعلم ذو نمط التعلم السمعي ، مثل : العهدة العصف

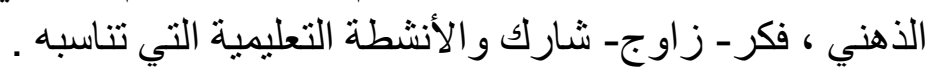

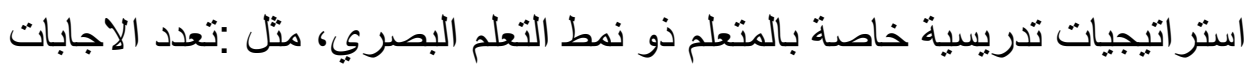
الصحيحة ،عقود التعلم و الأنشطة التعليمية التي تناسبها.

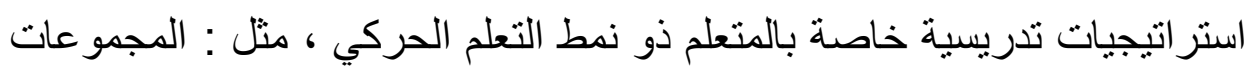
المرنة ، لعب الادوار و الأنشطة التعليمية التي تناسبه.

\section{مصطات البحث: - (ل)}

\section{التعليم المتمايز: Differentiated-Instruction}

يُعرف بأنه: فلسفة تدريسية تساعد المعلم علي تطويع خطة الموقف التعليمي تبعا

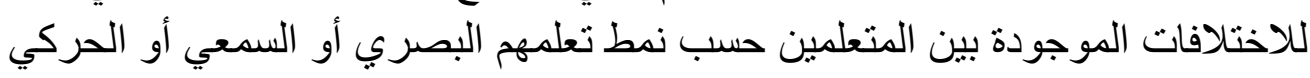

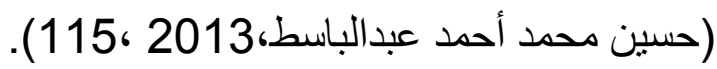

كما يُعرف بأنه: تعليم مرن يوفر لجميع الطلاب فرصا مناسبة ومتوازنة لتعلمهم بما

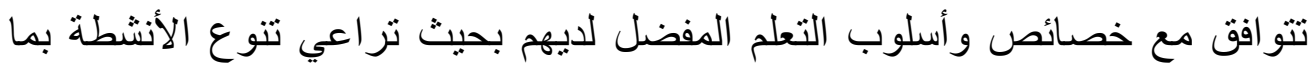

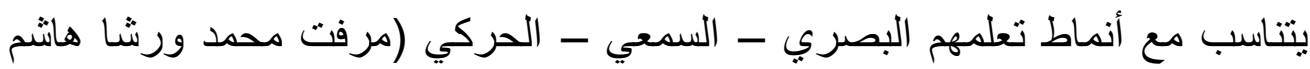
.) 136 ، 2017،

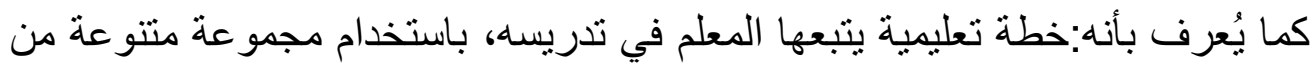

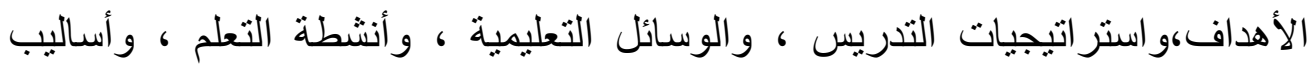


التقويم ، لتلبية احتياجات الطلاب ذوي القدرات و أنماط التعلم والاهتمامات المختلفة (شيماء محمد علي ،2016 ، 2016 ، 58 ) ).

ويعرف إجر ائيا بأنه: مجموعة من الاستر اتيجيات والأنشطة التعليمية المختلفة ،التي

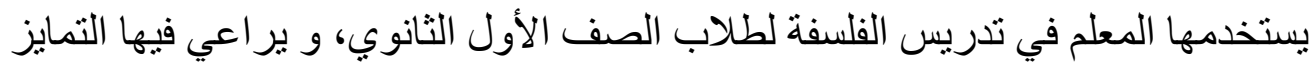
و الفروق الفردية بينهم ، بهدف تثمية بعض مهار ات التعلم المنظم ذاتياً.

\section{مهارات التطلم المنظم ذاتياً: Self-Regulated Learning Skills}

تعرف بأنها : عملية بنائية نشطة يستطيع المتعلم من خلالها القيام بتحديد الأهداف

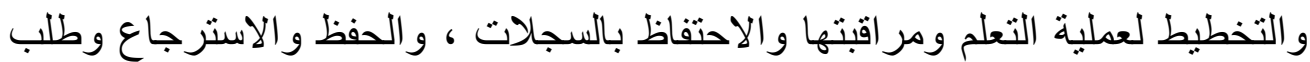

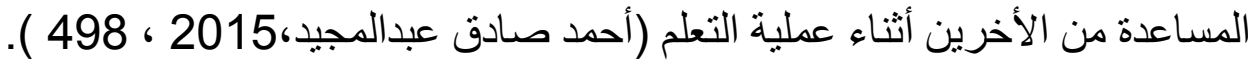

كما تعرف بأنها :عملية عقلية معرفية منظمة ، يكون فيها المتعلم مشاركا نشطا في عملية تعلمه ، ويقوم فيه بعمليات التخطيط وصياغة الأهداف ، و والتنظيم ، و الاستخدام

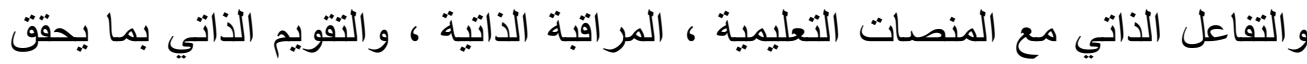
هدفه من التعلم (هبة هاثم محمد ، 2017 ، 107 ) ).

وتعرف إجرائيا بأنها : قدرة طلاب الصف الأول الثانوي على تتظيم تفكيرهم و انفعالاتهم وسلوكهم من خلال القيام بمجموعة من العمليات البنائية النشطة أثناء الثياء در استهم لمادة الفلسفة ، مثل التعامل مع المفاهيم الفلسفية، التعامل مع الذات، إدارة بيئة التعلم، ضبط إجر اءات التعلم.

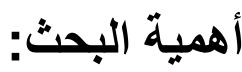

تتمثل أهمية البحث في أنه قد يفيد كلا من:

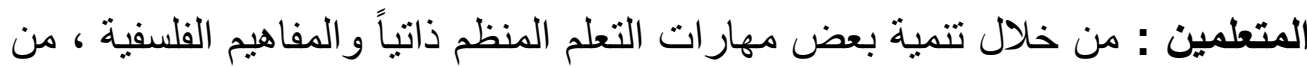

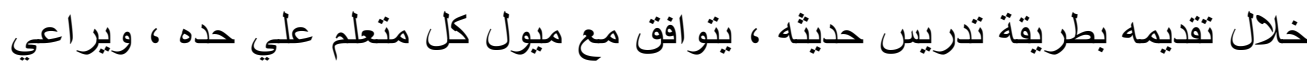

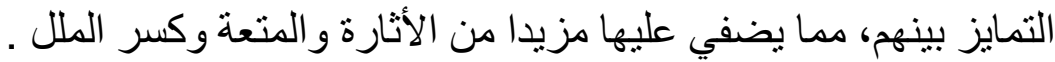

المعلمين: يقدم دليل معلم يوضح كيفية استخدام التعليم المتمايز في تدريس الفلسفة، كما يقدم مقياس لبعض مهار ات التعلم المنظم ذاتياً.

الباحثين :يتيح المجال أمام الباحثين لإجراء بحوث ودر اسات مرتبطة باستخدام التعليم المتمايز في تدريس المو اد الاجتماعية و المو اد الأخرى مع متغير ات التين جديدة . 
القائمين علي تخطيط المناهج: توجيه نظر القائمين علي تعليم الفلسفة والاجتماع إلي

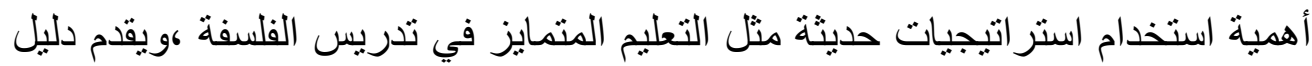
(كتاب الطالب) في الفلسفة يصاغ وفقًا استر اتيجية التعليم المتمايز.

\section{الإطار النظري للبحث:}

أولا: مفهوم التعليم المتمايز:

يُعرف بأنه عمل منظومة من استراتيجيات التدريس (عقود التعلم -

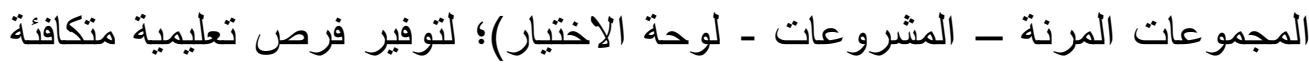

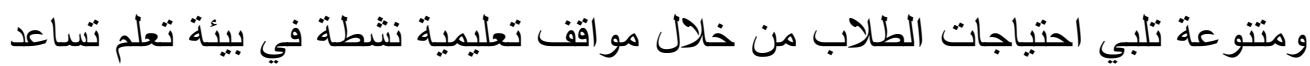

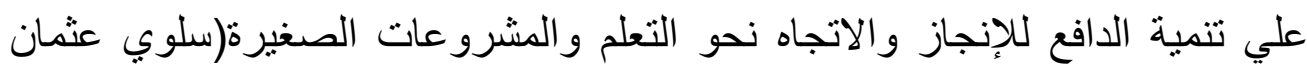

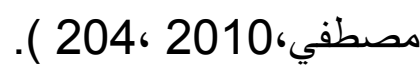

ويُعرف بأنه تعليم متمركز حول الطالب ،يقوم علي تنويع استراتيجيات

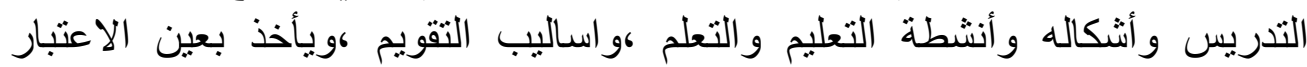

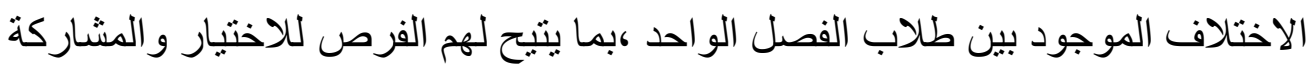

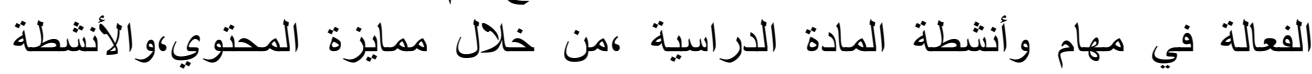
والاستراتيجيات وأساليب التقويم وفقا لاستعدادات التلاميذ (كريمة عبد التئ اللاه

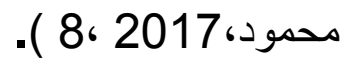
ثناتيًا: أهداف التعليم المتمايز: ويري (2002,12) (Heacox (2014)، مها سلامة نصر(18) 78 )، مشاعل مهدي(2018، 104 ) أن التعليم المتمايز يحقق أهداف متنو عة تكمن فيما يلي: - يعمل التعليم المتمايز علي توفير الفرصة لجميع الطلبة للعمل والتعلم من خلال الأنشطة المختلفة مر اعيا بذلك الأنماط المختلفة للتعلم. - المرونة والقابلية للتعديل لكل من محتوي المادة التعليمية وطريقة التدريس ومخرجات المادة التعليمية.

- يكسب الطلاب بعض المهار ات مثل المنافسة، و القدرة علي التحدي و الكسب. 


\section{ثالثًا: أهمية التعليم المتمايز:}

تتمثل أهمية التعليم المتمايز في الحاجة لتنويع التدريس في المواقف التعليمية، لأن

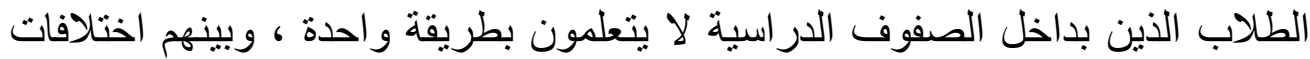

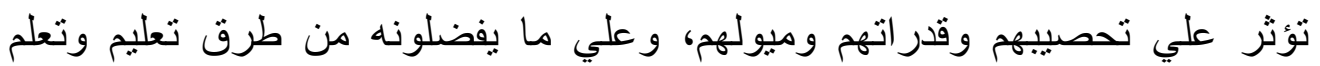

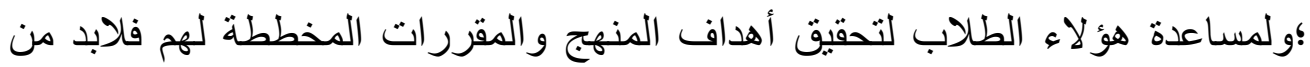

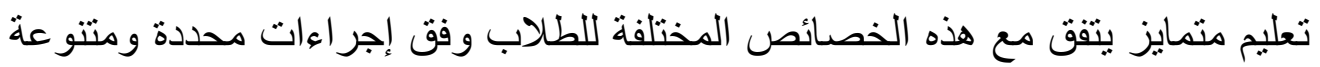

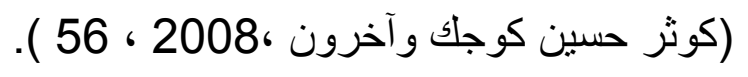

رابعًا: مبررات استخدام التعليم المتمايز:

Differentiated- من المبررات التي دعت إلي استخدام التعليم المتمايز

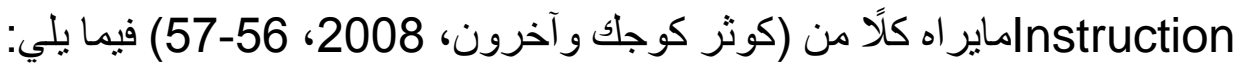
- طبيعة المتعلمين : حيث كل منهم لديه استعداد للتعليم ، وتختلف ميولهم وقدر اتهم ،و لايتعلمون بطريقة واحدة حيث لاتتناسب مع جميع المئ المتعلمين.

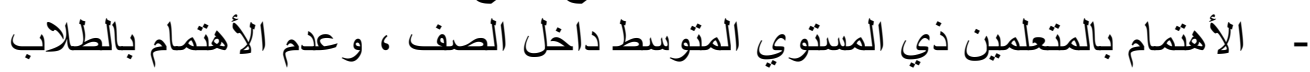
المتقدمين و الضعفاء. - حقوق الإنسان: تنويع التدريس في التعليم حق من حقوق الإنسان ، تنص عليه

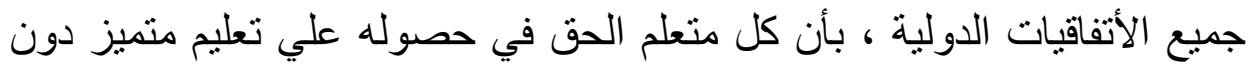

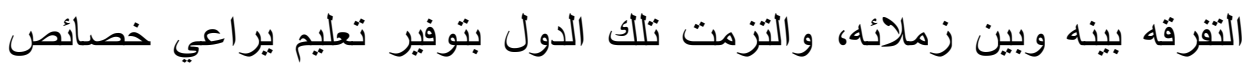

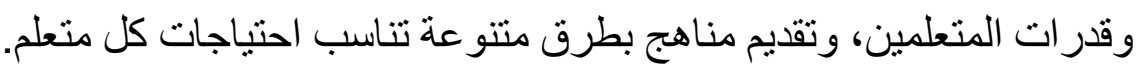

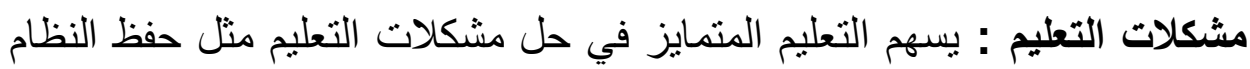
داخل الفصل ، كثافة الفصول ، قلة الفئل الإمكانيات.

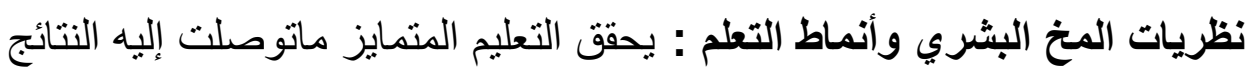

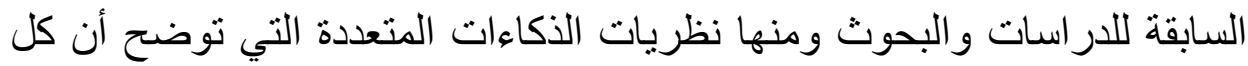
فرد لديه مجموعة من الذكاءات المتعددة تتفاوت من فرد لآخر ، وأن وأن كل متعلم

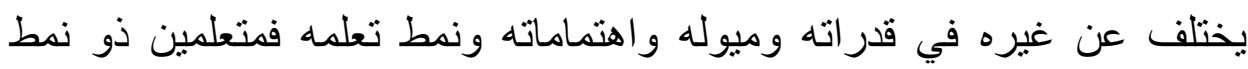

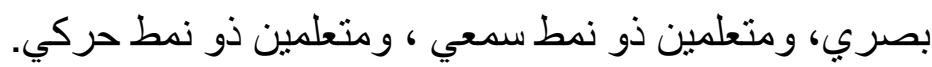

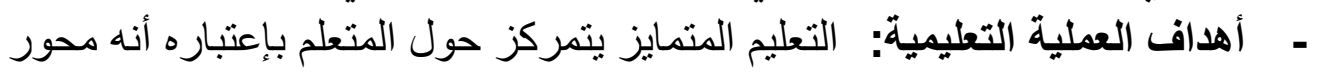
العملية التعليمبة. - دافعية المتعلمين: يخلق التعليم المتمايز الدافعية للتعلم لدي المتعلمين لأنه بعتمد علي التحدي الإيجابي بينهم. لمين. 
خامسًا: استراتيجيات التعليم المتمايز: يتضمن التعليم المتمايز العديد من الاستر اتيجيات ، أهمها ما يلى :

فكر زاوج شارك: Share ،Pair ،Think

تعتمد هذة الأستر اتيجية علي استثارة التلاميذ لكي يفكروا كلًا علي حدة، ثم

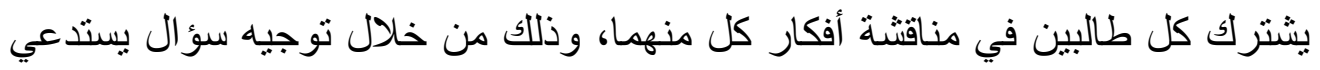

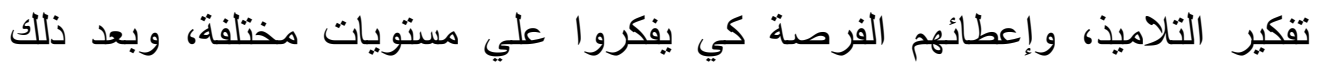

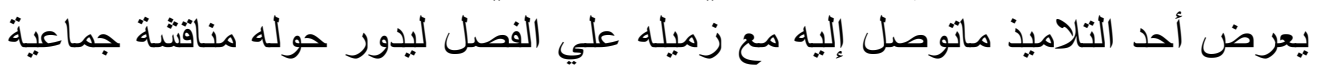

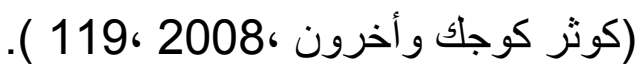

\section{Learning Contracts: عقود التعلم}

هذة الإستراتيجية عبارة عن عقد اتفاقًا يتم بين المعلم والمتعلمين وفيها يمنح

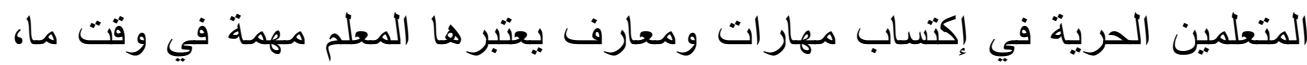
وينص هذا العقد علي غرض العملية التعليمية بشكل مقنع للمتعلمين، والأنشطة

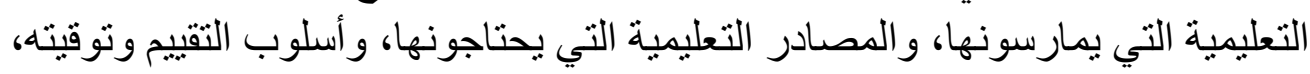

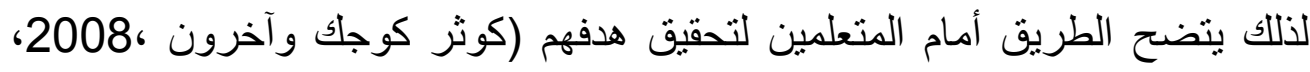

المجموعات المرنة: Flexible-grouping

هي عبارة عن مجمو عات مختلفة يكون كل طالب في الفصل عضوًا فيها ،ويتم

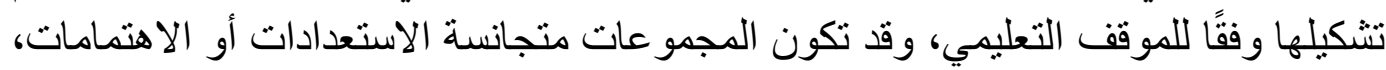

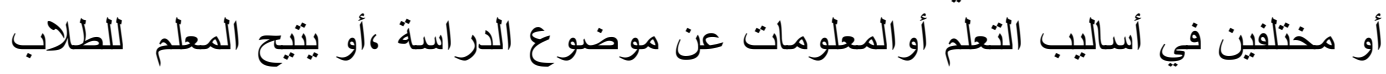

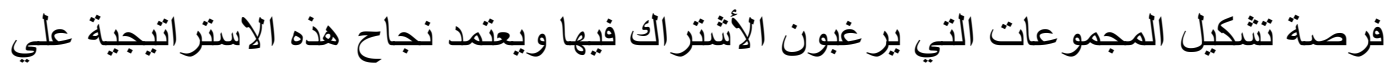

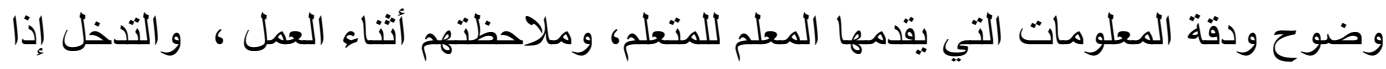

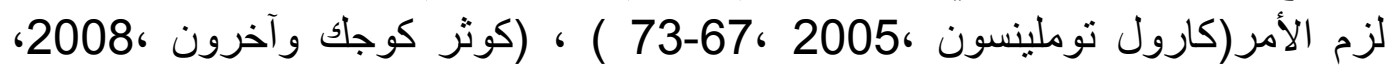

.(124-123

\section{العصف الذهني: Brainstorming}

ويُعد العصف الذهني موقف تعليمي يستخدم من أجل توليد أكبر عدد من الأفكار للمشاركين في حل مشكلة مفتوحة خلال فترة زمنية محددة في جو تسوده 
الحرية والأمان في طرح الأفكار بعيدًا عن المصادرة والتقييم أو النقد، ودور المعلم في

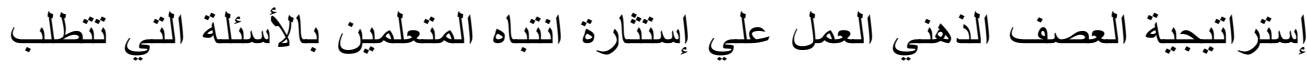

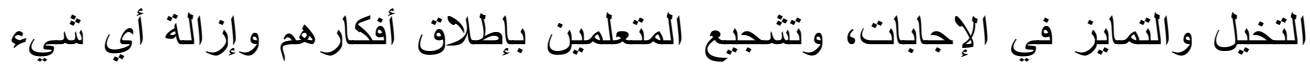

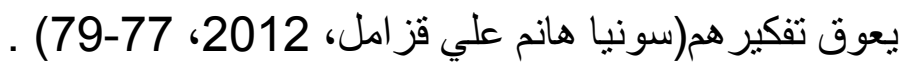

\section{learning centers : أركان التعلم ومراكزه}

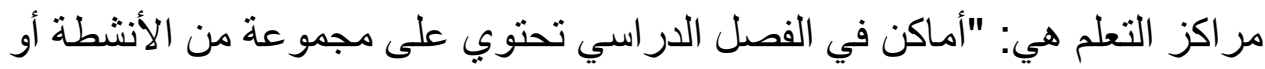

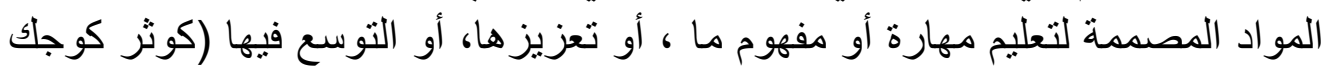

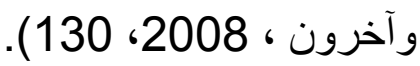

\section{سادسًا: التعليم المتمايز وتدريس القلسفة}

ينظر التربويين حديثًا إلي العملية التعليمية نظرة تجعل التعلم يتمركز حول المتعلم ،

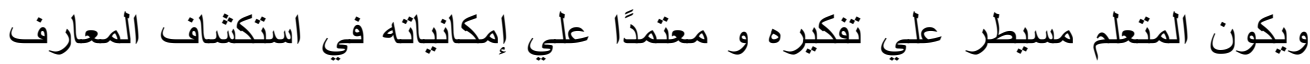

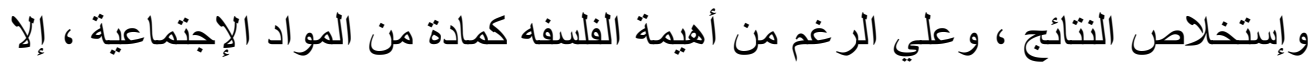

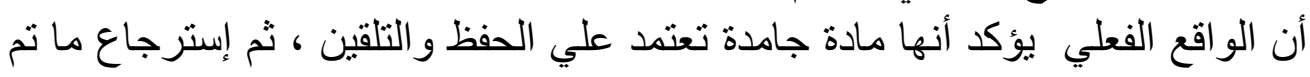

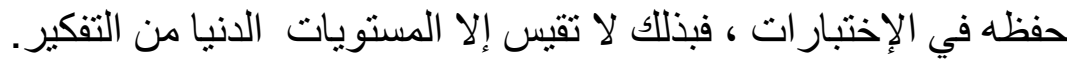

وبما أن العملية التعليمية محور ها الرئيسي المتعلم في إكتساب المعارف والمعلومات

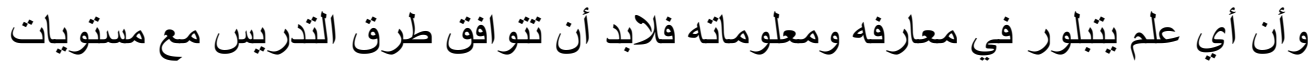

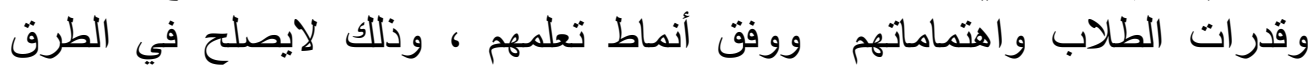

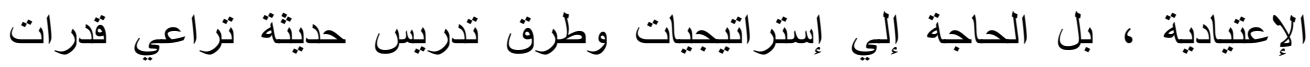

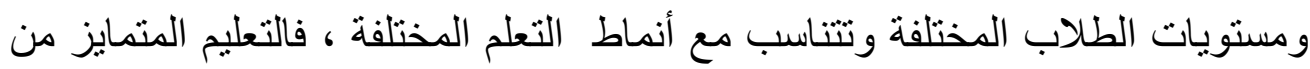

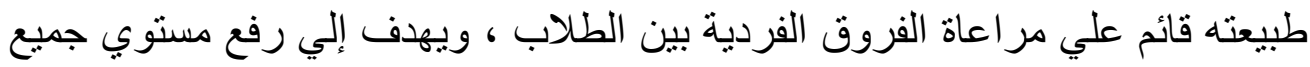
الطلاب .

المحور الثاني: مهارات التعلم المنظم ذاتيًا أولًا: مفهوم التعلم المنظم ذاتيًا

تعرفه مكة عبدالمنعم محمد البنا (2013، 118) ـ بأنه قدره الطالب علي استخدام

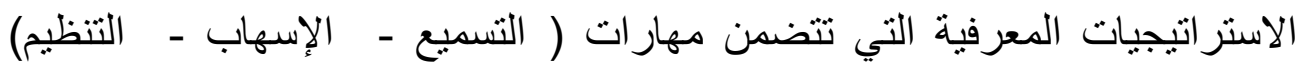

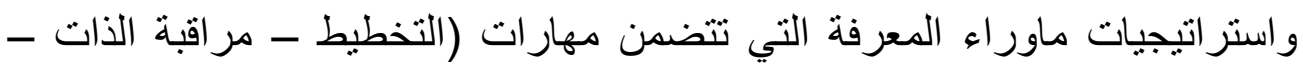


التقويم الذاتي ) و إستر اتيجيات إدارة المصدر و التي تتضمن مهار ات ( تنظيم بيئة التعلم و إدارة الوقت - تتظيم الجهد - البحث عن مساعدة - تعلم الأقران ).

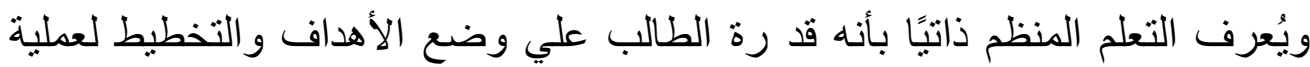

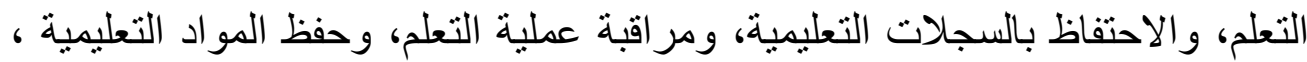
وطلب العون من الأخرين (عبدالناصر الجراح، واليجة 2010، 339).

ثانيًا :أهمية مهارات التعلم المنظم ذاتيًا لاى طلاب المرحلة الثانوية

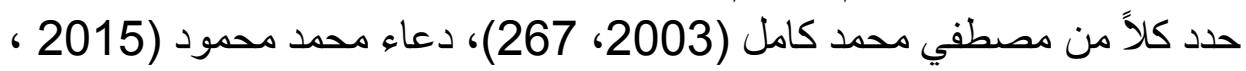

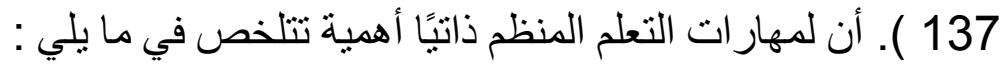

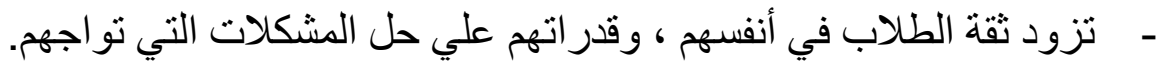

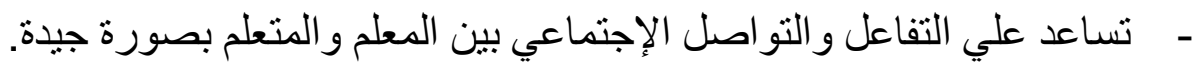

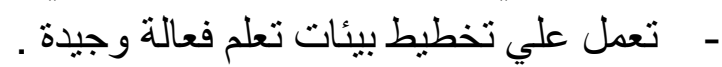

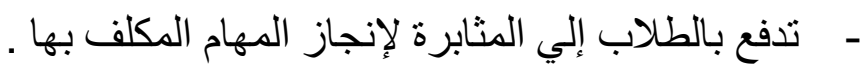

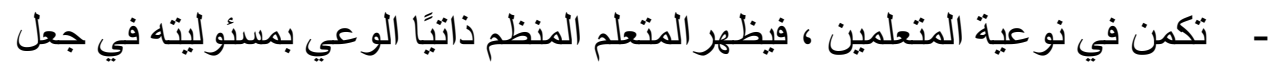

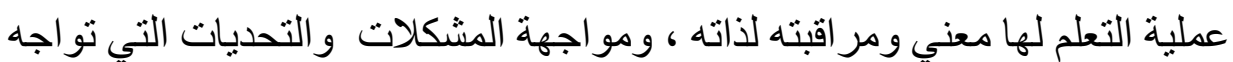

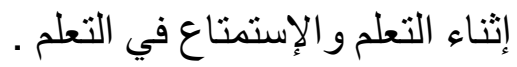

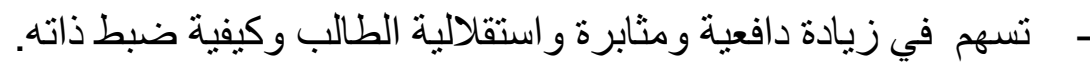

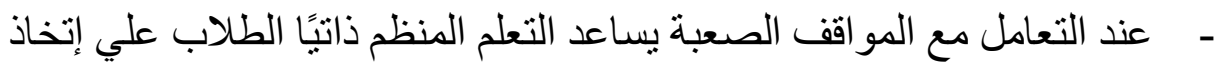
القررات الصائبة.

ثالثًا: مميزات مهارات التعلم المنظم ذاتيًا وقد ذكر طارق عبدالرعوف (2015، 49-50 ).أن مهار ات التعلم المنظم ذاتيًا له عدة

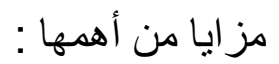

- تطور أهداف عملية التعلم ويحدد أهداف واقعية لكل طالب بحيث يجد أهداف تعليمية تناسب حاجاته و قدر اته. - زيادة الطلاب من خلال توفير التنوع في المو اد التعليمية و النشاطات و الأهداف .

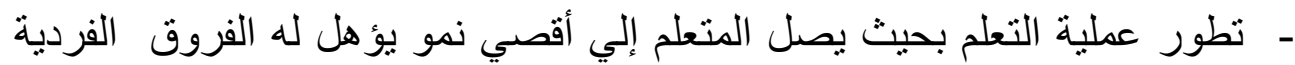

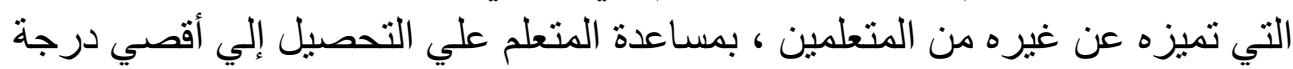
مدكنة عن طريق حاجاته التعليمية الفردية . - يتلقي فيها كل طالب التوجيه و الإرشاد و الر عاية من المعلم في جو من التقة و الأمن بعيدًا عن التشهير و الإحر اج بين الطلاب. 
- تعود الطلاب علي مواجهة المشاكل والعمل علي حلها مما يكون له الأثر الإيجابي علي نمو الطالب . - تتغلب علي الملل المتكرر في التعلم الجماعي.

رابعًا: مهارات التعلم المنظم ذاتيًا

أعدت أسماء (أسماء محمد عبدالحميد ، 2013 ، 341). مقياسًا للتعلم المنظم ذاتيًا

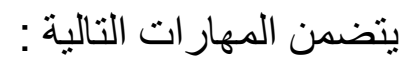

وضع الأهداف : و هو قدرة الطلاب علي تحديد أهدافهم من خلال عملية التعلم

و المهام التي يقومون بها.

التخطيط : قيام الطلاب بتحديد الإجر اءات التي يسيروا عليها في العملية

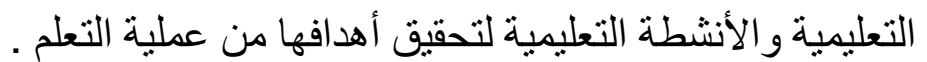

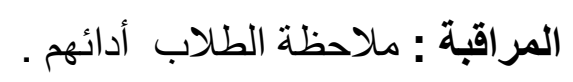

البحث عن المعلومات وطلب العون : الجهود التي يبذلها الطلاب في العصدي الحصول علي المعلومات و المعارف ذات الصلة بالمهمة وله وطلب العات العون من الآخرين. الدافعية : قدرة الطلاب في التغلب علي المشكلات التي تواجهم في العملية

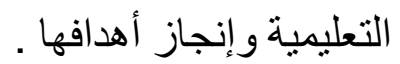

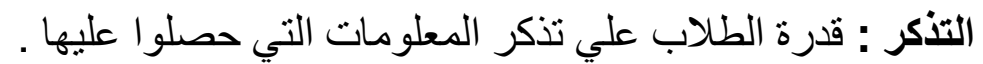

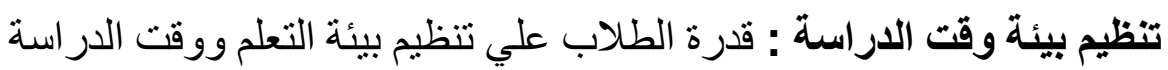

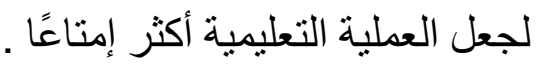

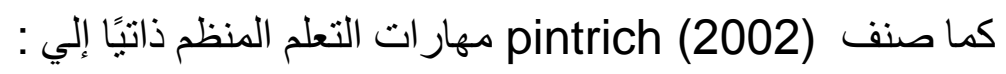

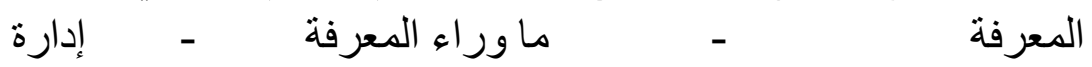
المصدر وبيئة التعلم وصنف البحث الحالي مهار ات التعلم المنظم ذاتيًا إلى اربعة مهار ات رئيسة

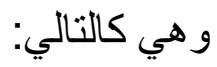
- - م التعامل مع المفاهيم الفلسفية.

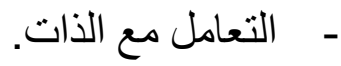

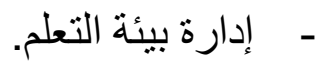

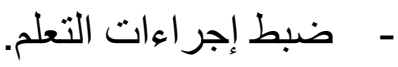


خامسًا : خصائص المتعلم المنظم ذاتيًا

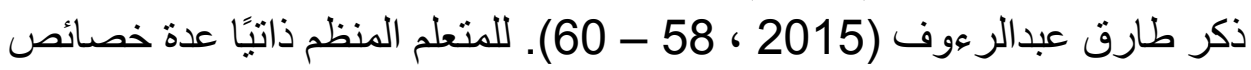

$$
\begin{aligned}
& \text { منها : }
\end{aligned}
$$

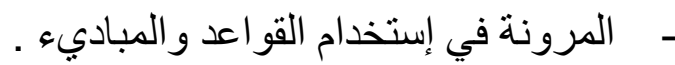

$$
\begin{aligned}
& \text { - } \\
& \text { - - القدرة علي التعاون مع الأخرين . - }
\end{aligned}
$$

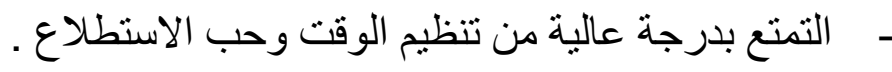

$$
\begin{aligned}
& \text { - - إمكانية وضع خطة و واضحة لإنهاء أعمالهم . } \\
& \text { - - يتميز بالمثابرة في عملية التعلم وتحمل المسئولية . } \\
& \text { - - الإستقلال في التفكير - - }
\end{aligned}
$$

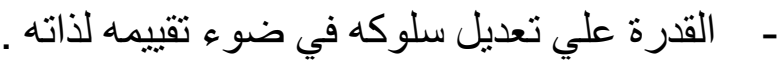
-

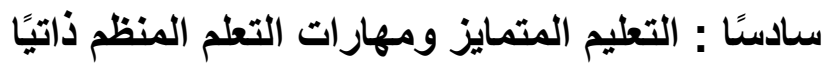

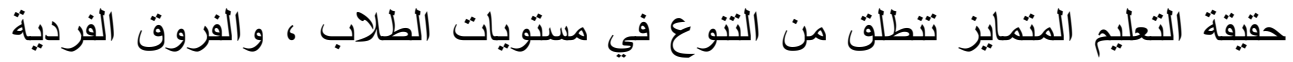

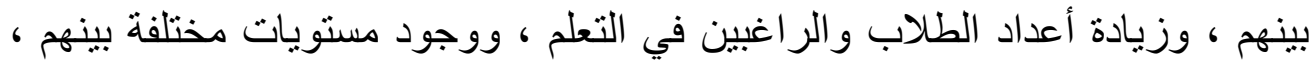

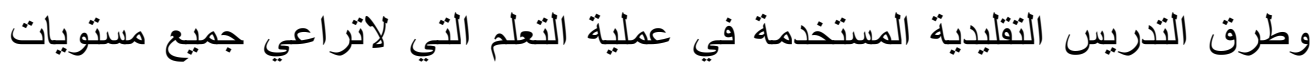

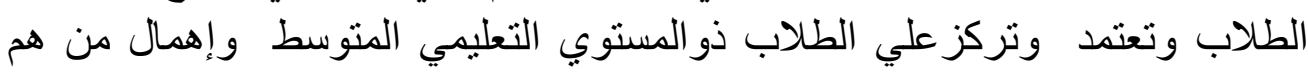
أعلي منهم أو أدني منهم في المسنوي التعليمي.

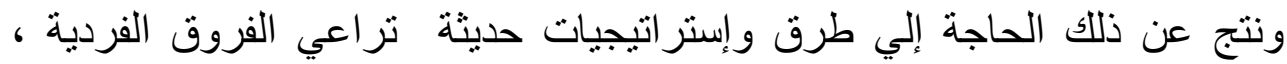

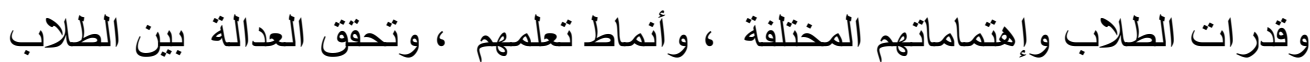

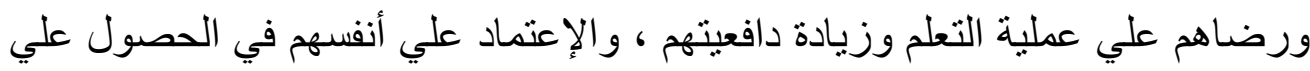
المعلومات و المعارف . فالتعليم المتمايز يهدف إلي رفع مستوي المتعلمين ، ليس الذين يواجهون مشكلات في دئ فئي

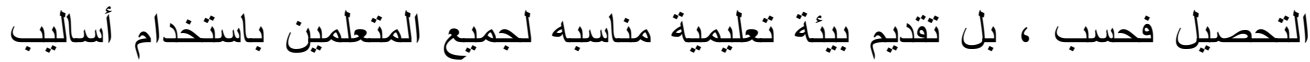

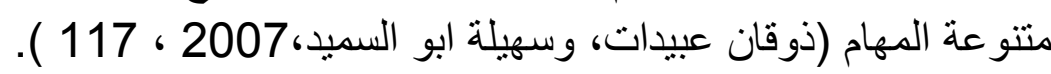

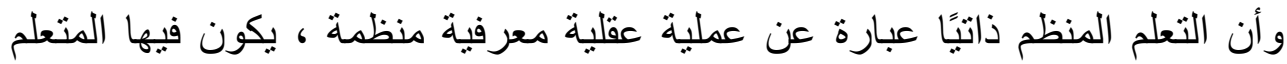

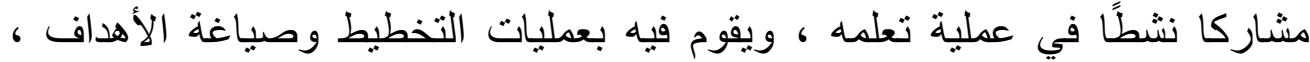

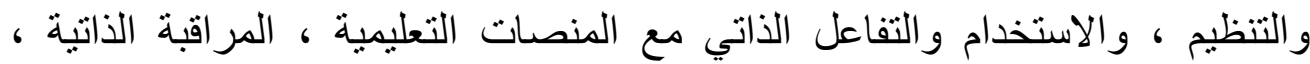
و التقويم الذاتي بما يحقق هدفه من التعلم (هبة هاتشم محمد ، 2017 ، 207 ، 107 ) ). فيتضمن التعليم المتمايزمجموعة من الطرق والإستر اتيجيات يستطيع من من خلاتلها المعلم أن ينمي بها مهار ات التعلم المنظم ذاتيًا ، لأن هدف التعليم التيم المتمايز تقديم بيئة 
تعليمية تتناسب مع جميع الطلاب ومثتوعة المهام ، مما يساعد الطلاب علي زيادة

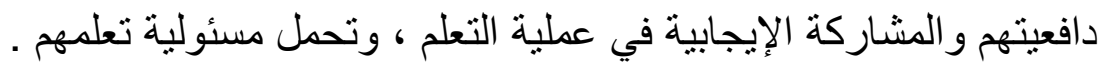

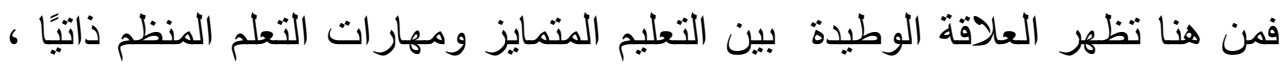

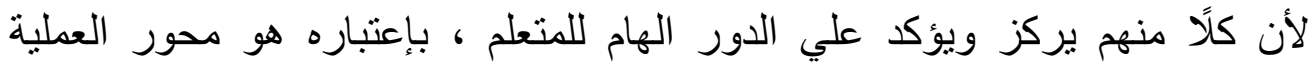
التعليمية . لان كلية

\section{منهج وتصميم البحث:}

يعتمد البحث علي المنهج شبه التجريبي القائم علي تصميم المجموعات المتكافئة من

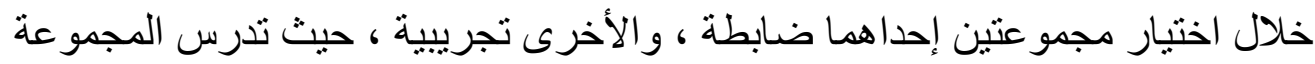

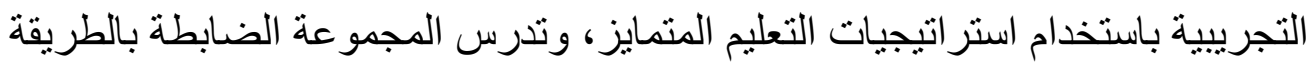

$$
\text { الجرألوفة والسائدة. }
$$

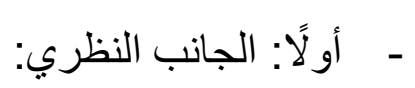

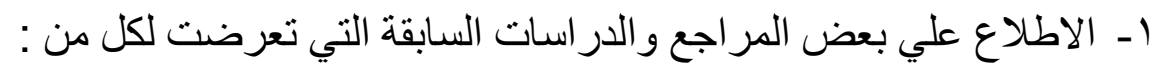

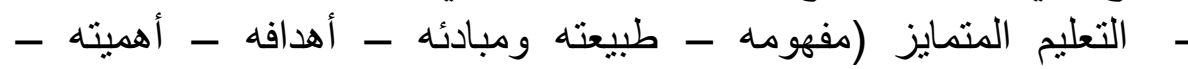

استر اتيجياته وتطبيقها في تدريس الفلسفة ـ دور المعلم المعلم في تفعيله ).

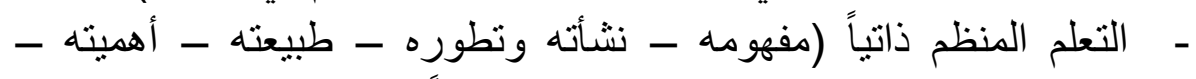

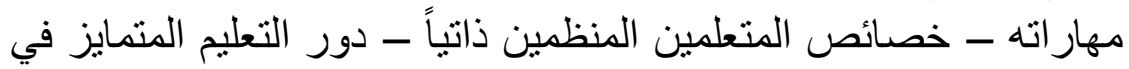

$$
\begin{aligned}
& \text { تنميته). } \\
& \text { - إعانيًا: الجانب التجريبي: }
\end{aligned}
$$

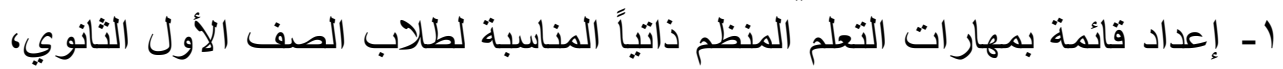

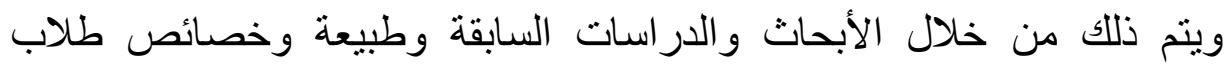

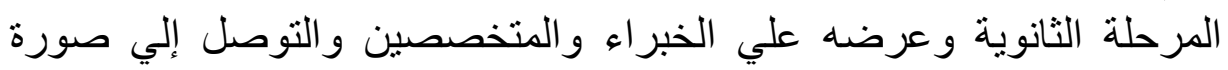

$$
\text { نهائية منها. }
$$

r- إعداد كتاب الطالب للوحدة الأولي لكتاب الفلسفة للصف الأول الثانوي، و عرضه

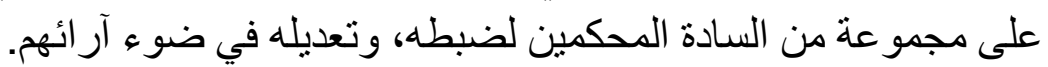

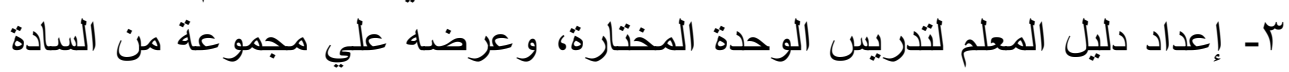

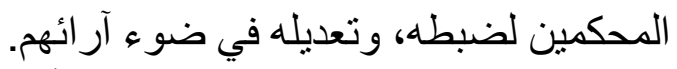
ع- إعداد مقياس لمهار ات التعلم المنظم ذاتياً و عرضه فئه علي الخبر اءه و والمتخصصين و التوصل إلي صورة نهائية منه. 
○ـ اختيار مجمو عة الدر اسة من طلاب الصف الاول الثانوي .

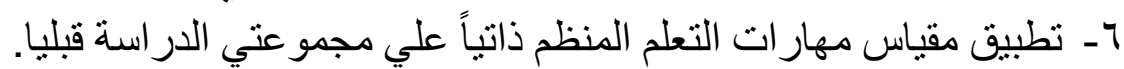

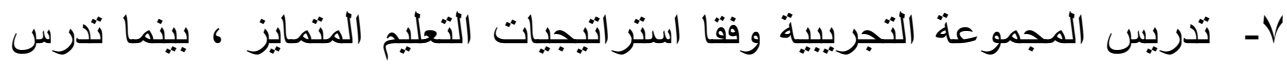
المجمو عة الضابطة بالطريقة المعتادة.

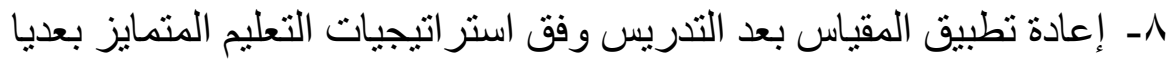

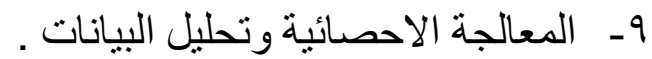

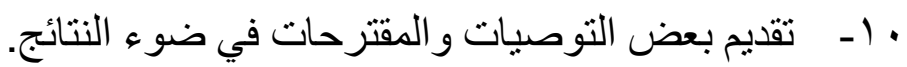

\section{نتائج البحث}

من خلال المعالجة الإحصائية التي حققها أفراد العينة في التطبيق القبلي و البعدي لكل

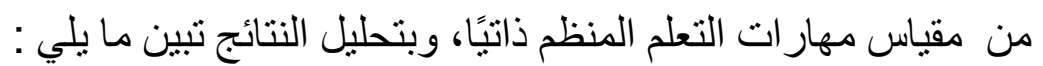

$$
\text { اـ التطبيق القبلي لأداتي الدراسة : }
$$

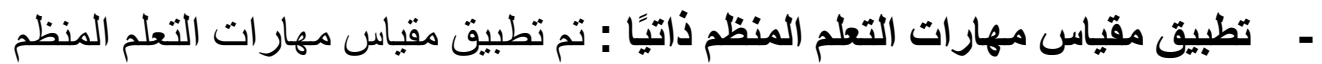

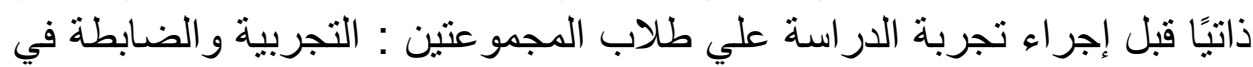

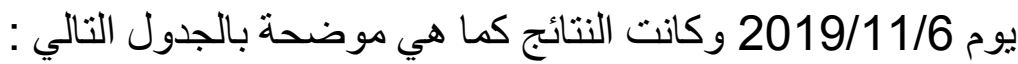
جدول (1)

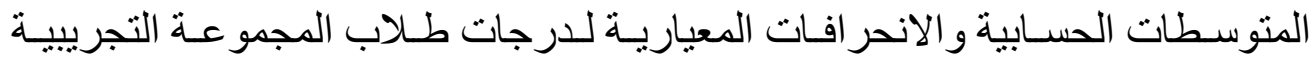

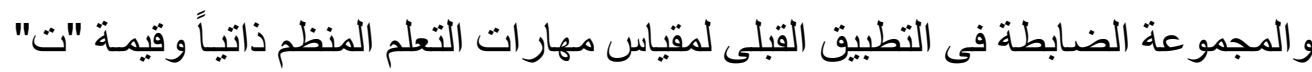
و الدلالة الإحصائية

\begin{tabular}{|c|c|c|c|c|c|}
\hline مستوى الدلالة & $\ddot{ت}$ & $\varepsilon$ & r & ن & المجموعة \\
\hline \multirow{2}{*}{ غير دالة } & \multirow[t]{2}{*}{$1 . r r$} & 1.91 & 1.11 & $r_{1}$ & التجريبية \\
\hline & & 11.87 & 1.18 & $r_{1}$ & الضابطة \\
\hline
\end{tabular}

حيث: ن عدد أفر اد المجموعة ، م تعبر عن المتوسط الحسابي للارجات ، ع الاححر اف المعيارى للارجات

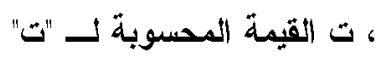

يتضح من جدول (1) أنه لا يوجد فرق دال إحصـائياً عند أى مستوى بين متوسطى

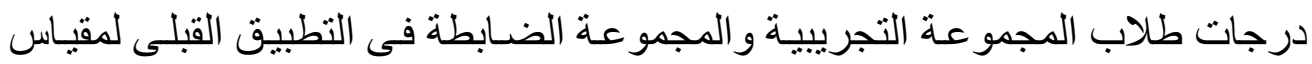

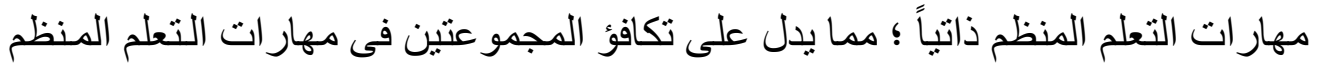

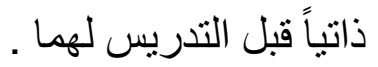




\section{r- التطبيق البعدي لأداتي الاراسة:}

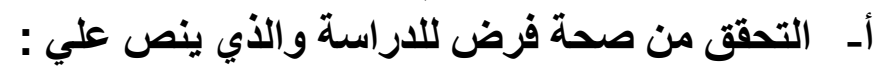

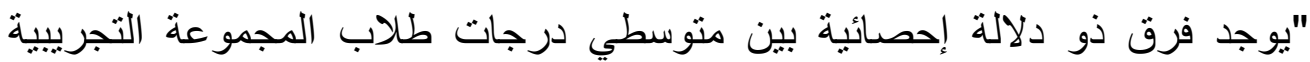

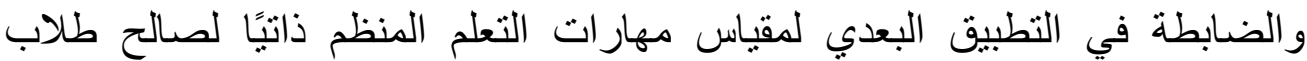
المجمو عة التجريبية ". وللتحقق من صحة هذا الفرض تم حساب المتوسطات الحسابية والانحر افات المعيارية لارجات طلاب المجموعة التجريبية والضابطة في التطبيق البعدي لمقياس مهارات التهات

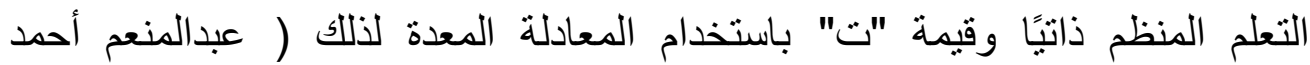
الاردير، 2006, 66) كما يتضح من.

جدول (Y) المتوسطات الحسابية والانحر افات المعياريـة لدرجات طلاب المجموعتين

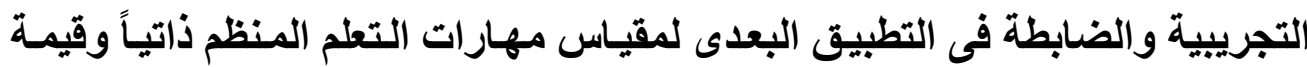

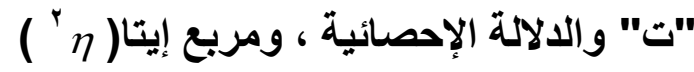

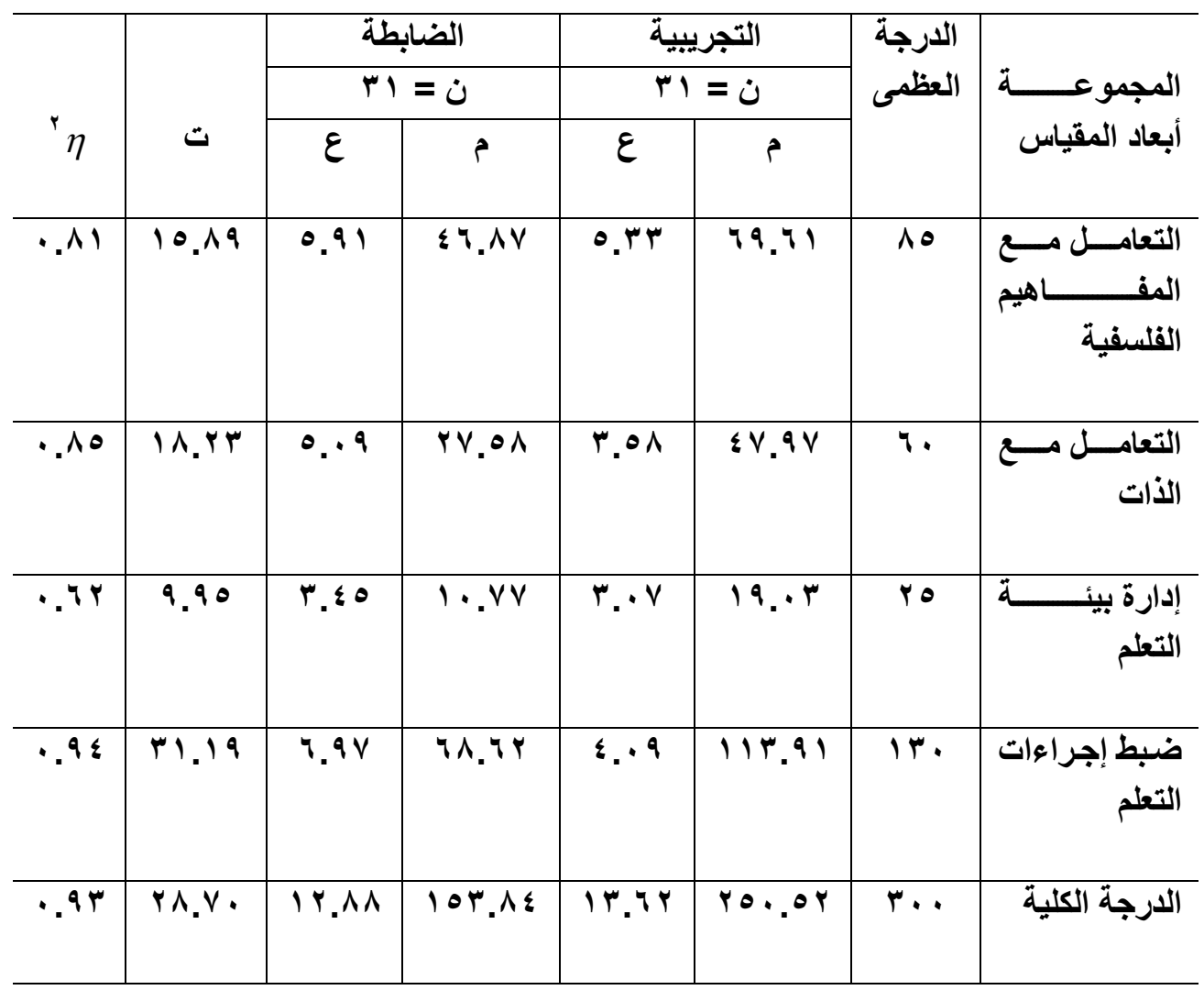


حيث: ن عدد أفر اد المجموعة ، م تعبر عن المتوسط الحسابي للارجات ، ع الاتحر اف المعيارى لللارجات

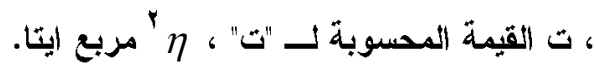

يتضح من جدول (2)، أنه يوجد فرق دالة إحصائيًا عند أي مستوي من مستويات الدلالة بين متوسطي درجات طلاب المجموعة التجريبية والمجموعة الضابطة في التطبيق البعدي لمقياس مهار ات التعلم المنظم ذاتبًا لصالح طلاب المجمو هة التجريبية ؛ و هذة النتيجة تؤكد صحة الفرض الأول من فروض الار اسة ، ويتضح ذلك في كل بعد

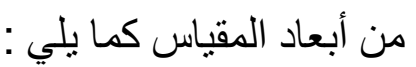
وجود فرق ذو دلالة إحصائية بين منوسطي درجات طلاب المجموعة التجريية و المجموعة الضابطة في القياس البعدي لمهارة التعامل مع المفاهيم لصالح المجموعة التجرييية والذي بلغ متوسط درجات الطلاب فيه (69.61) وهو أكبر من منوسط درجات طلاب المجموعة الضابطة و الذي بلغت قيمته (46.87). وجود فرق ذو دلالة إحصائية بين متوسطي درجات طلاب المجموعة التجريبية و المجموعة الضابطة في القياس البعدي لمهارة التعامل مع الذات لصالح المجموعة التجريبية والذي بلغ متوسط درجات الطلاب فيه (47.97) وهو أكبر من متوسط درجات طلاب المجموعة الضابطة و الذي بلغت قيمته (27.58). وجود فرق ذو دلالة إحصائية بين متوسطي درجات طلاب المجموعة التجريبية و المجموعة الضابطة في القياس البعدي لمهارة إدارة بيئة التعلم لصالح المجموعة التجرييية والذي بلغ متوسط درجات الطلاب فيه (19.03) وهو أكبر من متوسط درجات طلاب المجموعة الضابطة و الذي بلغت قيمته (10.77). وجود فرق ذو دلالة إحصائية بين متوسطي درجات طلاب المجموعة التجريبية و المجمو عة الضابطة في القياس البعدي لمهارة ضبط إجر اءات التعلم لصالح المجموعة التجريبية والذي بلغ متوسط درجات الطلاب فيه (113.91) وهو أكبر من متوسط درجات طلاب المجموعة الضابطة و الذي بلغت قيمنه (68.62). 
ويوضح شكل (1) المتوسطات الحسابية لارجات طلاب المجموعة التجريبية

والمجموعة الضابطة في التطبيق البعدي لمقياس مهارات التعلم المنظم ذاتيًا :

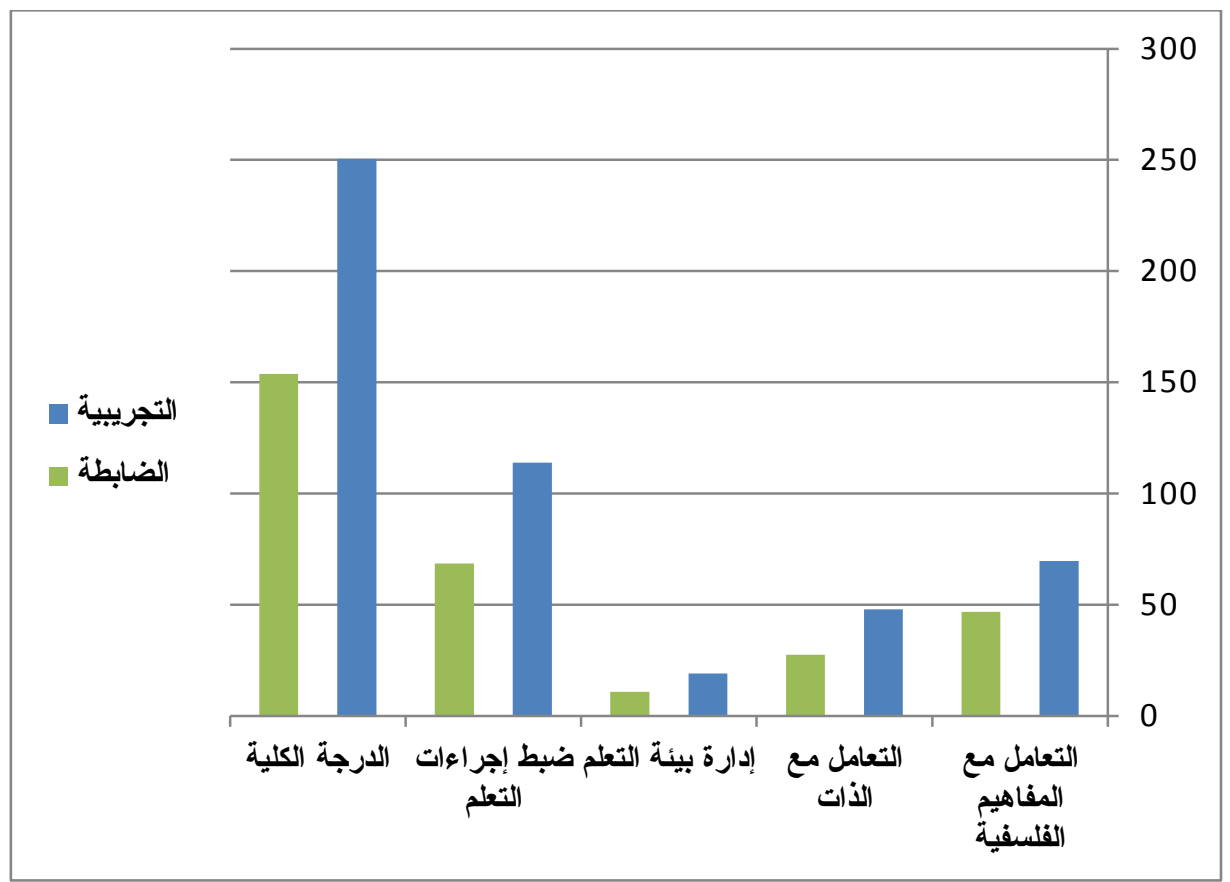

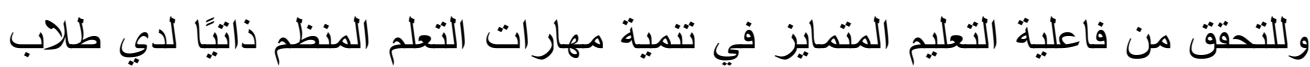

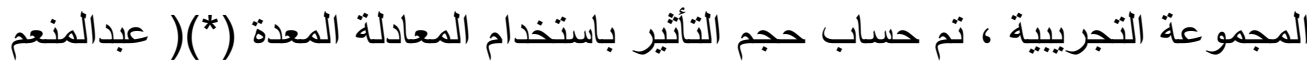

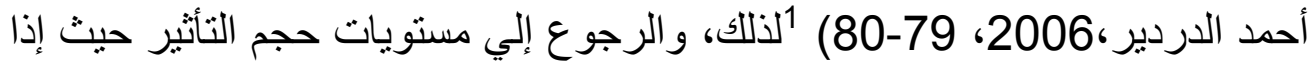

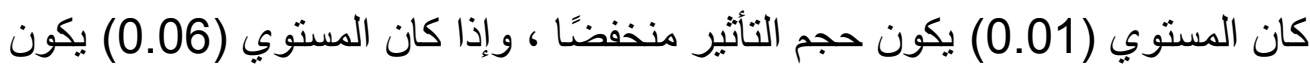

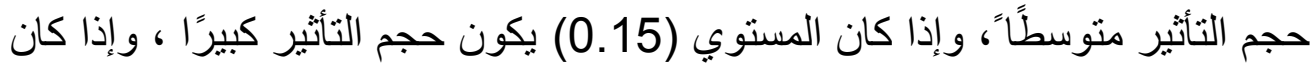

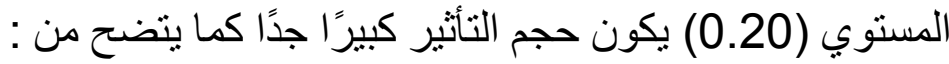

جدول (ץ) تحديد مستويات حجم التأثير

\begin{tabular}{|c|c|c|c|c|}
\hline كبير جداً & كبيز & متوسط & منخفض & المؤشر \\
\hline.$r$ & .10 & $\because 97$ & .1 & مربع آيتا \\
\hline
\end{tabular}

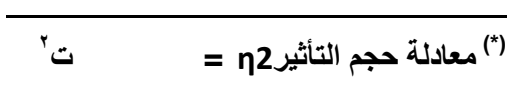

$$
\begin{aligned}
& \text { ت + + درجات الحرية }
\end{aligned}
$$

العدد الثاني والأربعون




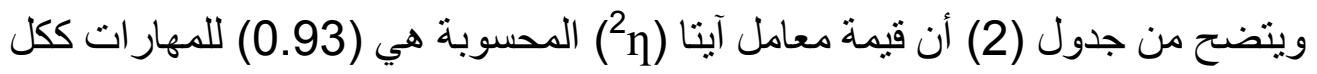

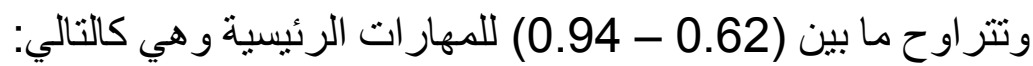

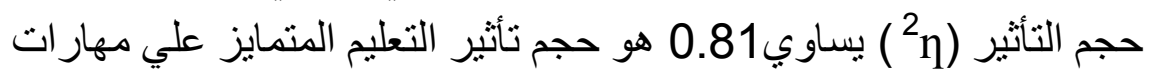

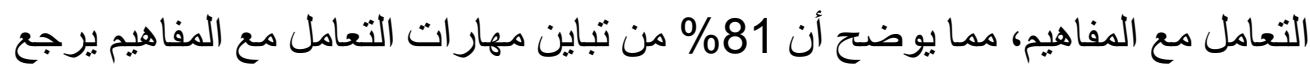
إلي تأثثير المتغير المستقل (التعليم المتمايز).

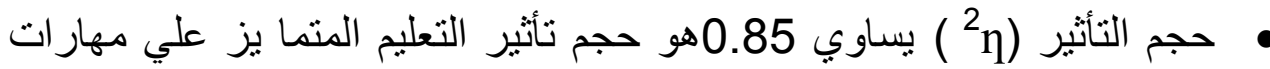

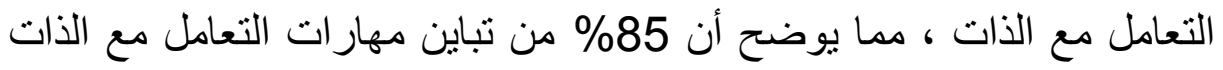
يرجع إلي تأثثير المتغير المستقل ( التعليم المتمايز).

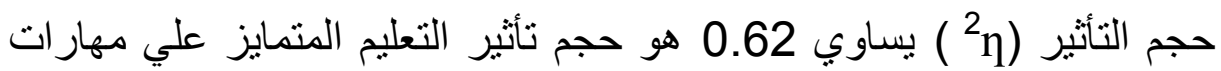

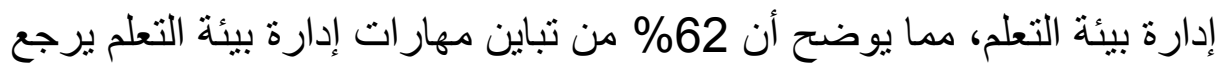

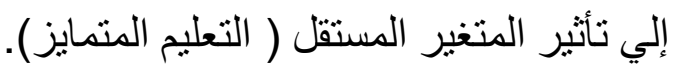
حجم التأثير (12 ) يساوي 0.94 هو حجم تأثثر التعليم المتمايز علي مهارات

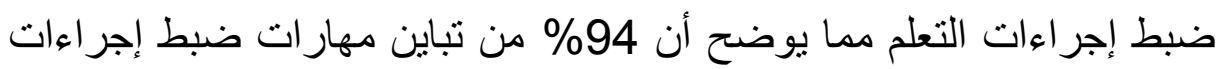
التعلم يرجع إلي تأثير المتغير المستقل ( التعليم المتمايز).

و هي قيم أكبر من القيم الموضحة في الجدول المرجعي لتحديد مستويات حجم التأثير

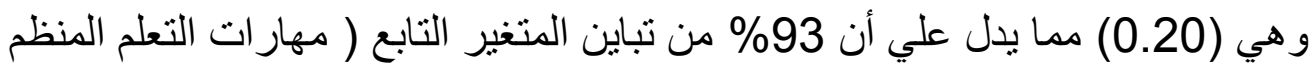

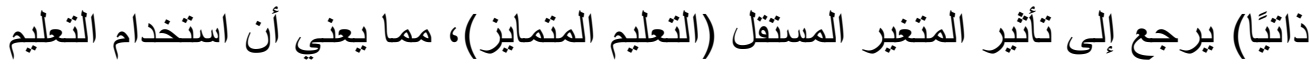

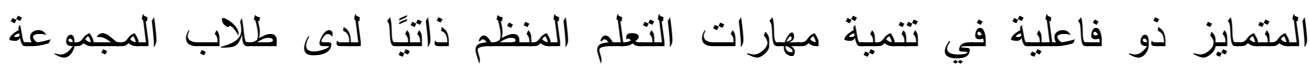

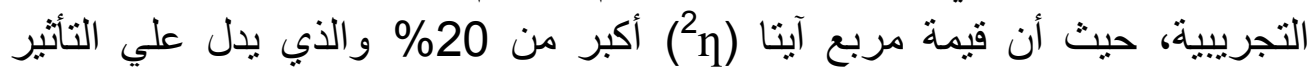
المرتفع للمتغير المستقل في المتغير التابع.

ويتضح من جدول (3) ، أن قيمة مربع آيتا (n²) المحسوبة أكبر من القيمة الموضحة

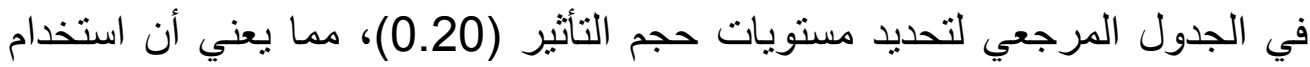

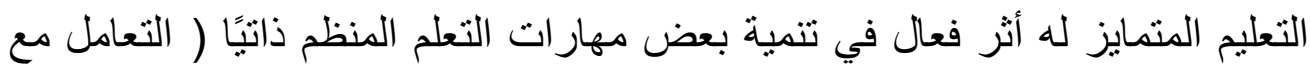

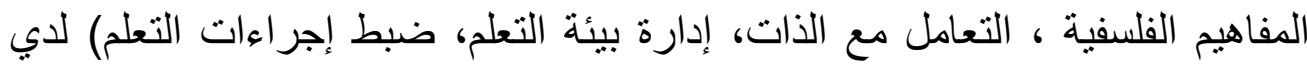
طلاب المجمو عة التجريبية .

\section{ثانيًا : مناقشة النتائج وتفسيرها}

بناءً علي النتائج التي تم التوصل إليها من خلال استخدام بعض استر اتيجيات التعليم

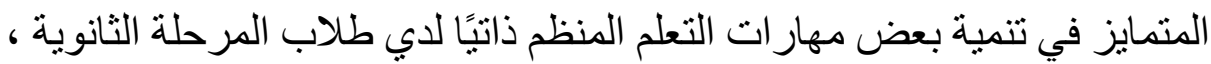

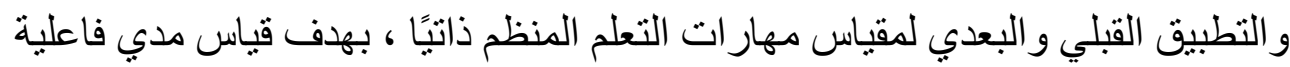


التعليم المتمايز في تنمية بعض مهار ات التعلم المنظم ذاتيًا لدي طلاب المرحلة الثانوية، يمكن تحليل هذه النتائج وتفسير ها علي عين النحو التالي . ا ـ - تحليل نتائج فرض الدراسة :

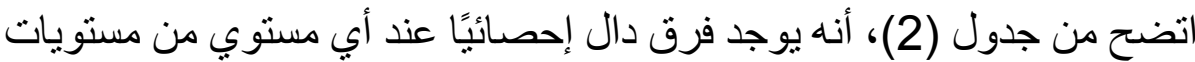

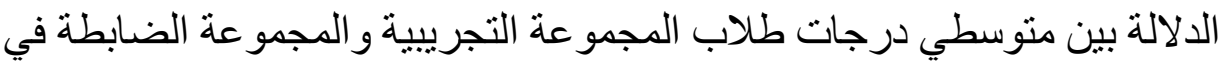

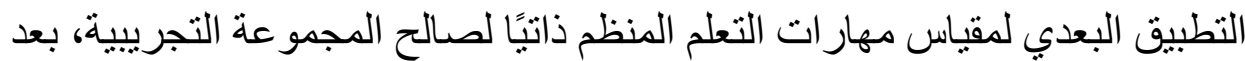

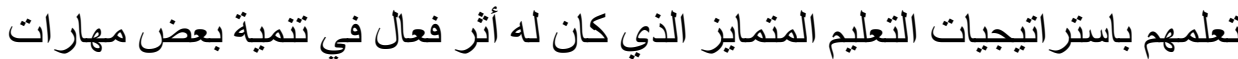

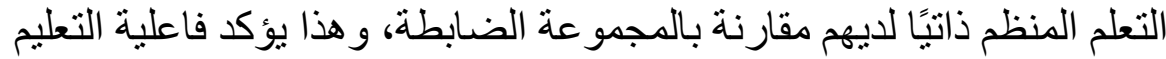

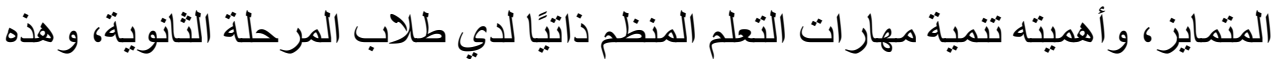

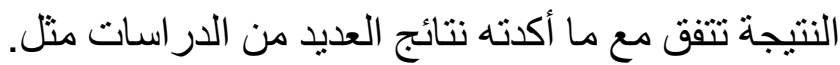

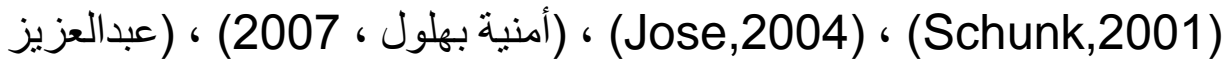

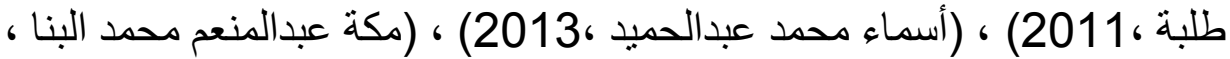
2013 )،( ربيع عبدالعظيم رمود ، 2011) ، 2015) . ويرجع الأثر الفعال للتعليم المتمايز في تنمية بعض مهرد ، مهارات التعلم المنظم ذاتيًا لاي طلاب المجموعة التجريبية إلي : لائي

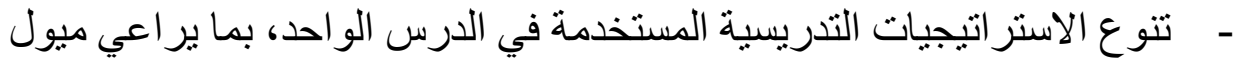
و اهتمامات الطلاب، ومستو ياتهم التحصيلية.

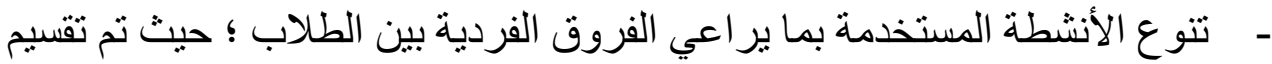
الطلاب إلي مجمو عات علي حسب أنماط تعلمهم ( بصري - سمعي - حركي ).

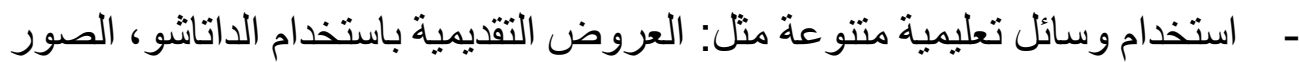
، البطاقات التعليمية ، جذب اهتمام الطلاب ومشاركتهن فئهم في العملية التعليمية.

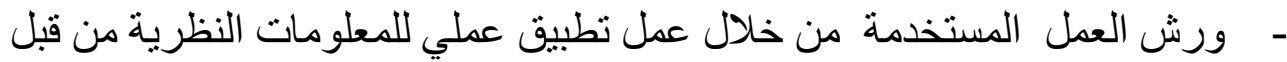
الطلاب و هذا ساعد علي تبسيط المعلومة وبقاء أثر تعلمها.

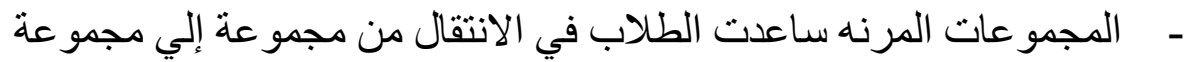

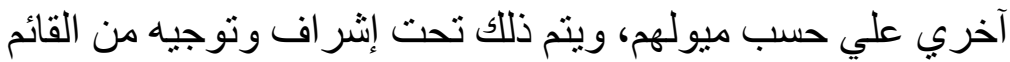
بالتدريس، كما يتم تسهيل انتقال الطلاب لتلك المجمو عات المر اد الانتقال

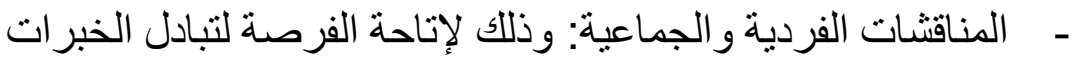
و المعلومات بين الطلاب، وتحفيز هم علي المشاركة، وتجنب الملل. 


\section{ثالثًا : توصيات الدراسة:}

في ضوء نتائج الدر اسة يمكن وضع التوصيات الآتية:

- عقد دورات تدريبية للمعلمين أثناء الخدمة لتدريبهم علي استخدام استر اتيجيات

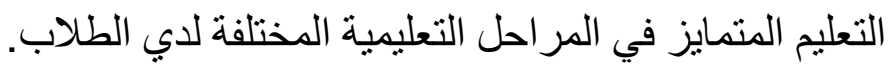

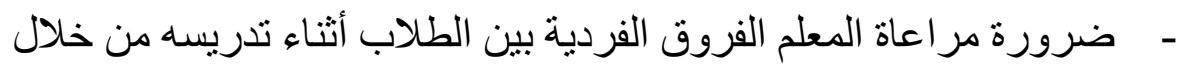

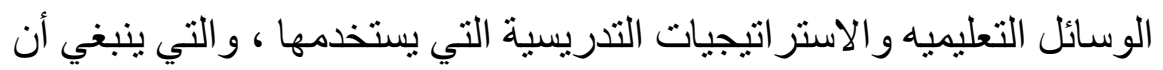

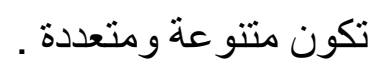

- الاهتمام بتتمية مهار ات التعلم المنظم ذاتيًا لدي المعلمين أثناء الخدمة بما ينعكس

$$
\text { إيجابيا علي تلاميذهم . الإنمان. }
$$

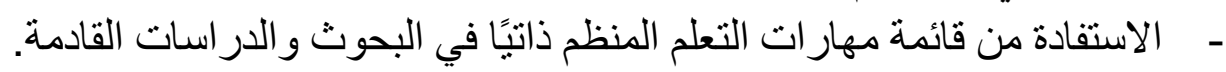

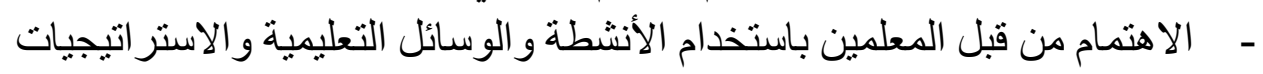

التدريسية التي تساعد على تنمية مهار ات التعلم المنظم ذاتيًا.

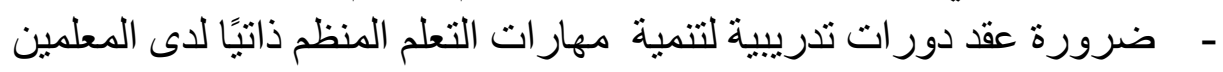

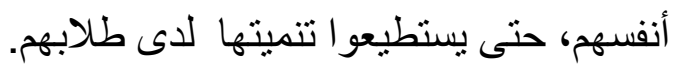

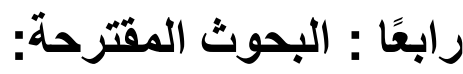

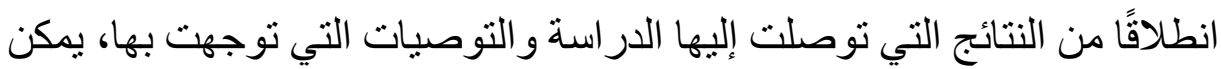
اقتر اح مجمو عة من الدر اسات التي تعد بمثابة در اسات مستقبلية يمكن أن تكون

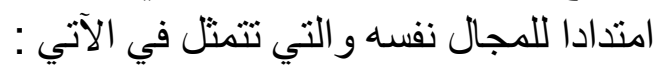

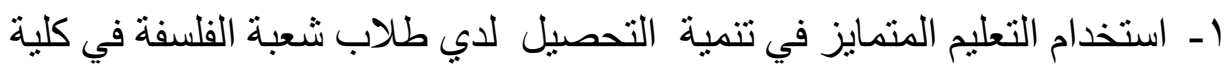

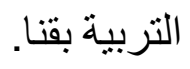

r- در اسة اتجاهات معلمي المو اد الفلسفية نحو استخدام بعض استر اتيجيات التعليم

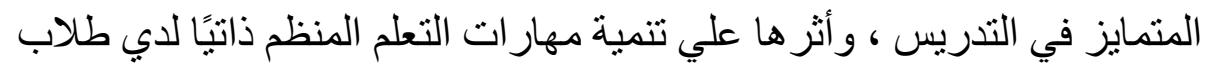

$$
\text { المرحلة الثانوية. }
$$

r- فاعلية استخدام استر اتيجية الأنشطة المتدرجة في تنمية بعض مهار ات التعلم

$$
\text { المنظم ذاتيًا لدي طلاب المرحلة التهابة الثانوية. }
$$

ع ـ فاعلية استخدام استر اتيجية عقود التعلم في تتمية بعض لابلة مهار ات التعلم المنظم ذاتيًا

$$
\text { لاي طلاب المرحلة الثانوية. }
$$

ــ التعليم المتمايز وتدريس الفلسفة. 
أحمد صـادق عبدالمجيد (2015 ). أثر استخدام استراتيجيات التفكير المتشعب في

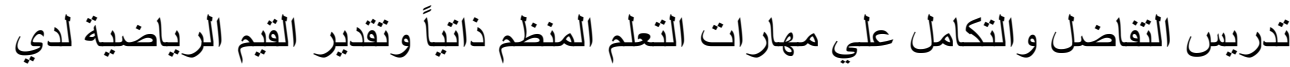
الطلاب المعلمين بكلية التربية ،المجلة التربوية ، الكويت ،

.461

أسماء محمد عبدالحميد ، سمية علي يس، عطيات محمد (2013 ). استخدام برنامج

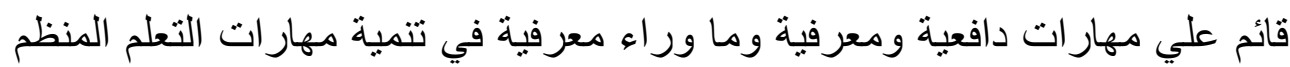

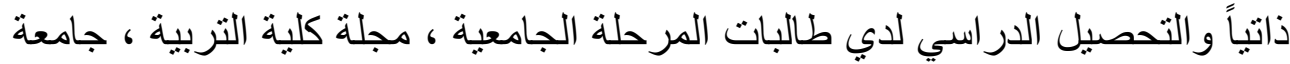

$$
\text { بنها ، } 24 \text { (94)، } 330 \text { - } 380 \text { - } 30
$$

تهاني بنت عبدالرحمن بن المزيني (2015 ). فاعلية استخدام أساليب التقويم البديل

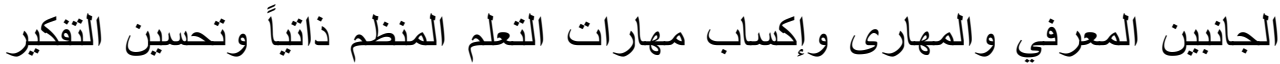

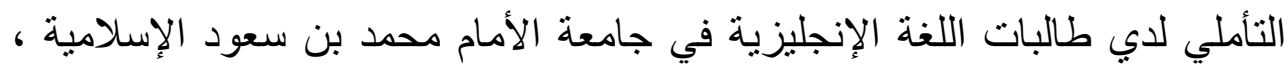

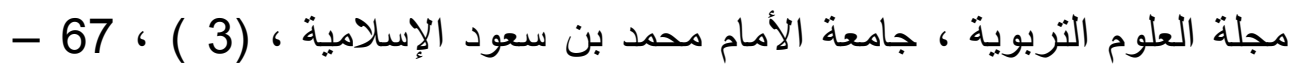

حسين محمد أحمد عبدالباسط (2013 ). فاعلية استخدام التعليم المتمايز في تدريس

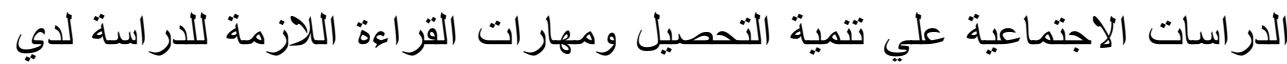

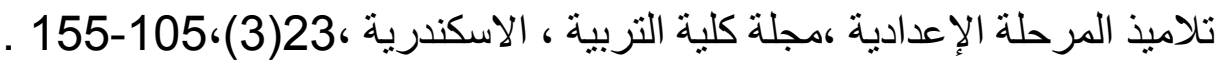
حنان أحمد حسين (2016 ). فاعلية نموذج تدريسي قائم علي التعلم المنظم ذاتياً في

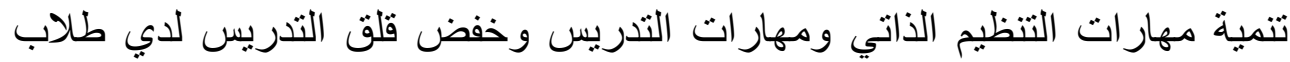
الدبلوم العام شعبة اللغة الإنجليزية، مجلة القر اعة و المعرفة، (لفية (179 )، 1- 40.

داليا فوزي عبدالسلام الثربيني (2017 ). استخدام التعليم المتمايز في تتمية التفكير

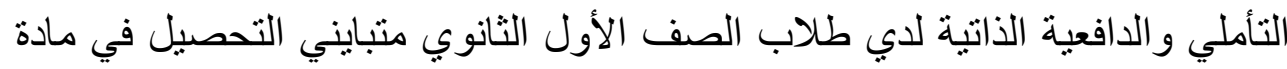
الجغر افيا ، مجلة الجمعية التربوية للار اسات الاجتماعية ، مصر ، 242 ، 925 ، 243.

دعاء محمد محمود (2015 ) ). برنامج قائم علي استخدام التعليم المتمايز لتنمية

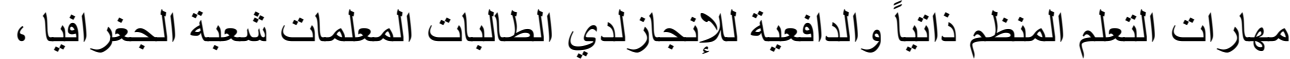

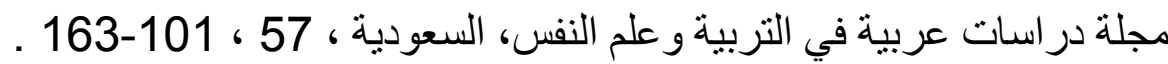


ذوقان عبيدات، سهيلة بو السميد (2007 ). استراتيجيات التدريس في القرن الحادي

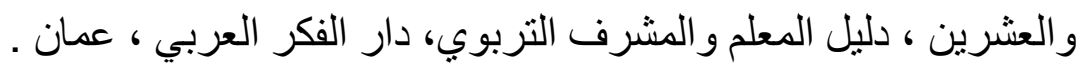
راندا مصطفي الديب (2014 ). الأصول الفلسفية للتربية، دار النابغة.

رجاء علي عبدالعليم ، رمضان حشمت محمد (2017). أثر التفاعل بين نمط تقديم الوكيل الذكي ومستوي التحكم فيه داخل بيئات التعلم الافتر اضية ثلاثية الأنية الأبعاد في

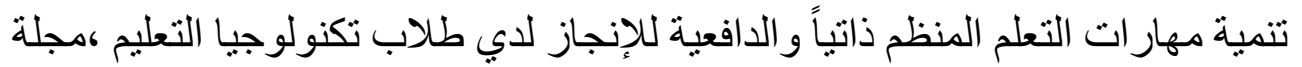

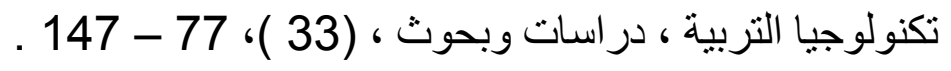

رجب عبدين مدبولي (2017). تدريس الفلسفة وتنمية مهارات التفكير التأملي و المفاهيم الفلسفية لدي طلاب الصف الأول الثانوي ، مجلة العلوم التربوية و النفسية ، كلية التربية ، جامعة الفيوم ،7(3) ، 179-228 .

سلوي عثمان مصطفي (2010 ).أثر استخدام تنويع استر اتيجيات التدريس Differentiated instructional Strategies الدافع للإنجاز و الاتجاه نحو التعلم والمشرو عات الصغيرة لدي تلميذات مدرسة الفصل

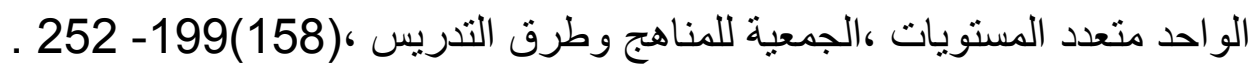
سونيا هانم علي قزامل (2012). طرق التدريس المعاصرة، القاهرة، عالم الكتب. شريهان محمد صديق (2017 ). فاعلية التعليم المتمايز في تدريس الدراسات

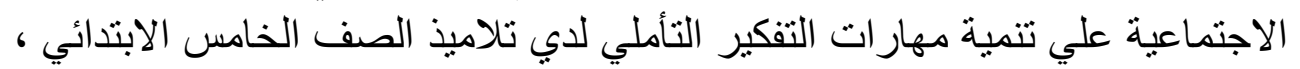
مجلة كلية التربية، جامعة بورسعيد ، (22 )، 959- 985 ( 985 ـ

شيماء محمد علي (2016 ). فاعلية برنامج قائم علي استر اتيجيات التدريس المتمايز في تنمية الكفاءة الرياضية لدي طلاب المرحلة الثانوية ،مجلة جمعية التربويات الرياضيات ، الجمعية المصرية لتربويات الرياضيات، 19 (5 )، 51 - 102 ـ طارق عبدالرعوف (2015 ). أسس ومفاهيم التعلم الذاتي ، القاهرة ،الدار العالمية. عبد المنعم أحمد الدردير (2006) ـ الإحصاء البار امتري و اللابار امترى ـ القاهرة : عالم الكتب . 
عبدالناصر الجراح (2010). العلاقة بين التعلم المنظم ذاتبًا والتحصيل الأكاديمي

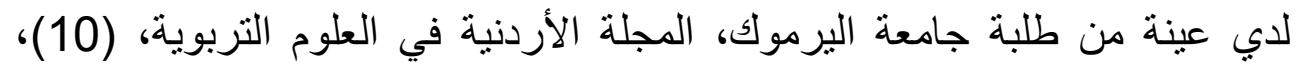
. 105 -38

عماد شوفي ملقي (2012) ـ تجريب التدريس المتمركز حول المتعلم في تطوير

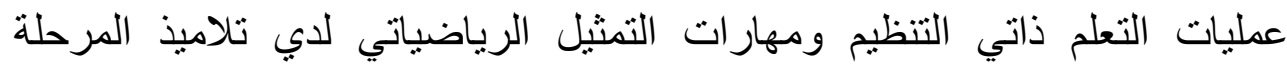

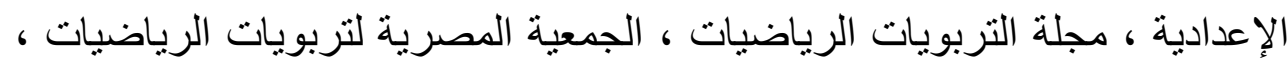
.64-19 ، 15

كارول آن توملينسون (2005 ). الصف المتمايز الاستجابة لاحتباجات جميع طلبة

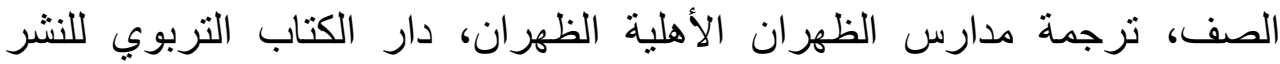
و التوزيع، المملكة العربية السعودية.

كريمة عبد اللاه محمود (2017 ). وحدة مقترحة في العلوم قائمة علي التعليم

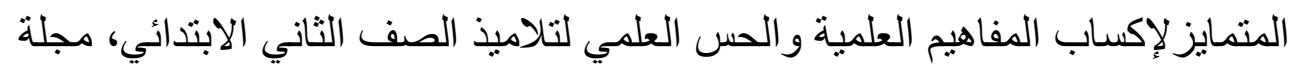

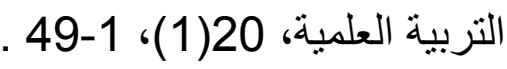
كوثر حسين كوجك ، و أخرون (2008 ). تنويع التدريس في الفصل دليل المعلم في التي تحسين طرق التعليم والتعلم في مدارس الوطن العربي ، مكتب اليونسكو الإقليمي

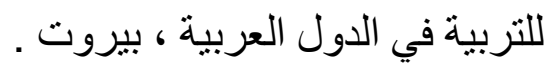

لطيفة بنت سر اج بن علي (2018 ).أثر استر اتيجية التعليم المتمايز في تتمية التفكير

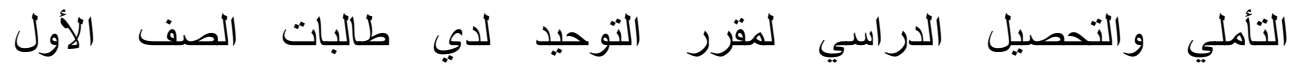

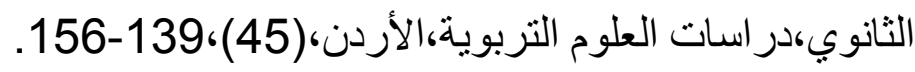

مرفت محمد كمال ورشا هاثم عبدالحميد (2017 ). توظيف التعليم المتمايز من خلال الكتاب الإلكتروني في تدريس الهندسة لتنمية المستويات التحصيلية العليا ومهارات

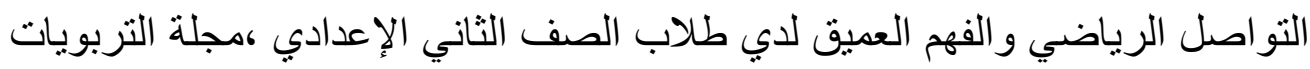
الرياضيات ، الجمعية المصرية لتربويات الرياضيات، 20 (4 )، 129 - 176 ـ

مشاعل مهدي سعيد الغامدي(2018 ). أثر استراتيجية التعليم المتمايز في تدريس التيس التئي

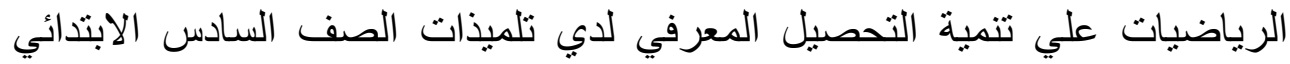

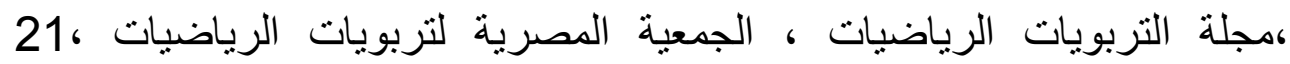

. $134-96 ،(2)$ 
مصطفي محمد كامل (2003). بعض المتغيرات المرتبطة بالتنظيم الذاتي للتعلم

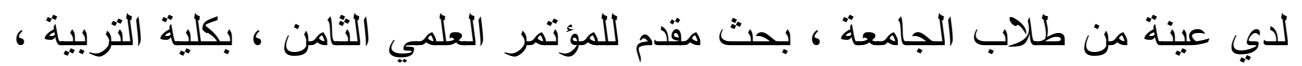

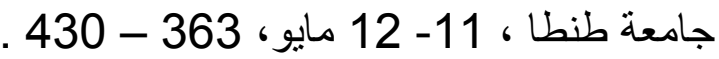

مكة عبدالمنعم محمد (2013 ). استراتيجية مقترحة في ضوء التعلم المنظم ذاتياً

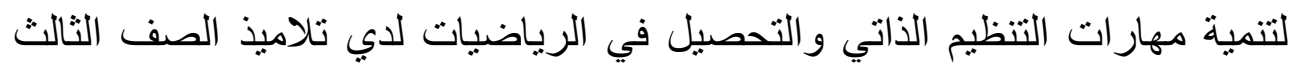
الاعدادي ، مجلة التربويات الرياضيات ، الجمعية المصرية لتربويات الرياضيات،

$$
\text { . } 178 \text { - 112، (4) } 16
$$

مها سلامة نصر (2014). فاعلية استخدام التعليم المتمايز في تنمية مهاراتي

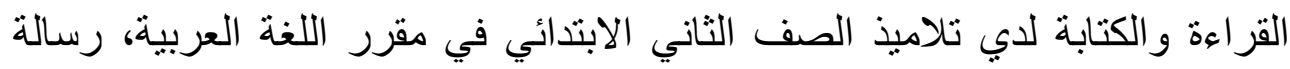

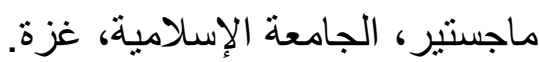

ميرفت محمود محمد (2016 ). بر امج لتنمية بعض مهار ات التعلم المنظم ذاتياً لدي

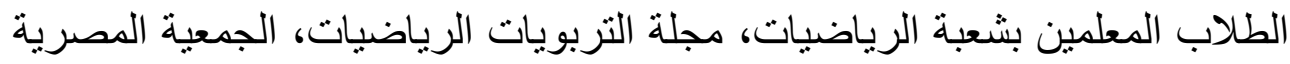

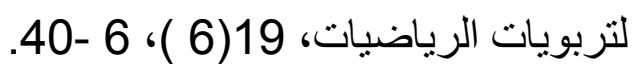

هالة الثحات عطية (2017 ). برنامج قائم علي استراتيجيات التعليم المتمايز في

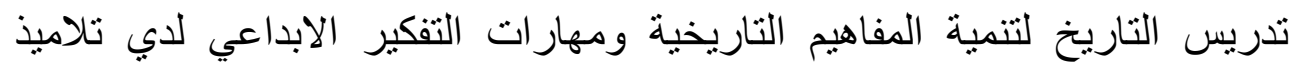

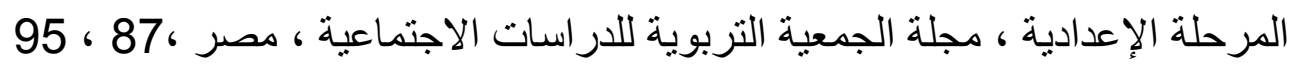
. 168 -

هبة هاشم محمد (2017).استخدام منصة Edmoda في تنمية مهارات التعلم المنظم ذاتياً والاتجاه نحو توظيفها في تدريس الدراسات الاجتماعية لطلاب الدبلوم العام بكلية التربية، مجلة الجمعية التربوية للار اسات الاجتماعية، مصر فورئ 90، 99-

هثام حبيب الحسيني (2006 ). نموذج مقترح للمكونات المعرفية وغير المعرفية

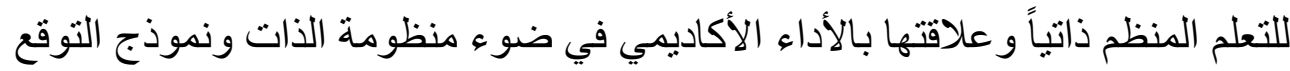

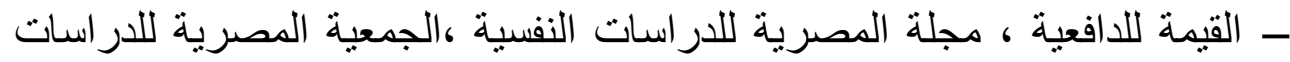

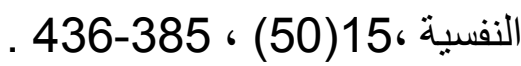


وحيد السيد حافظ و جمال سليمان عطية (2006 ). فاعلية برنامج قائم علي التعلم

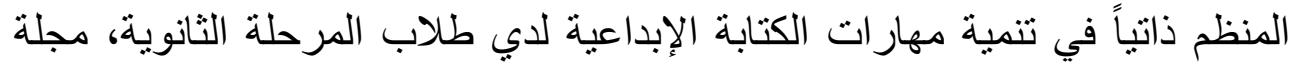

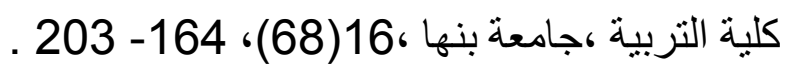

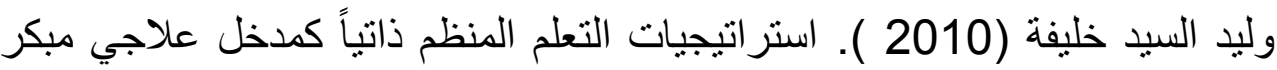

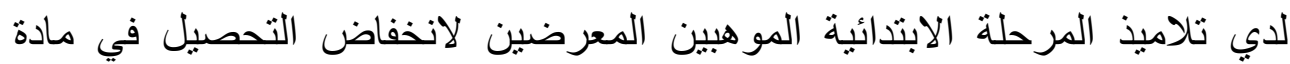

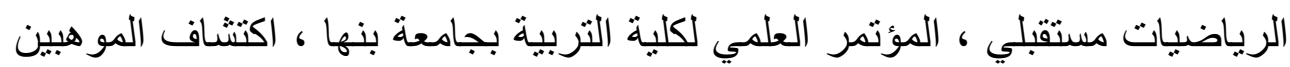

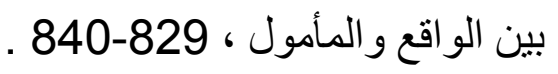

Bandura, A. (2002). Social Cognitive Theory in Cultural Context, journal of applied psychology: an International Review, 51, 269-290.

Bahlool, A. (2013). The Effect of Differentiated Instruction Strategy on Developing Ninth Graders' English Reading Comprehension Skills at Gaza UNRWA Schools. MA thesis, the Islamic University of Gaza.

Chamberlin, M \& Powers, R. (2010). The promise of differentiated instruction for enhancing the mathematical understandings of, college students, Journal of Teaching mathematics \& its Application , 29(3), 113- 139.

Heacox, D. (2002). Differentiating Instruction in the Regular Classroom; How to Reach and teach all learners, Grades 3-12by, Free spirit publishing.

Hubbard, D. A. (2009) "The Impact of different tiered instruction for English language learners at the secondary level with focus on gender", M.A thesis California state University.

Ruohotie, P. (2002). Motivation and Self - regulation in learning, in: Ruohotie, $\mathrm{p}$ \& Niemi, $\mathrm{H}$ : Theoretical 
understanding for Learning in the Virtual University, Finland: RECE, pp.37-70.

Schunk, D. H. (2001). Social cognitive theory and selfregulated learning. In: Zimmerman B. J. \& Schunk D. H. (Eds.), Self-regulated Learning and academic achievement: theoretical Perspectives, Springer, New York, ( $2^{\text {nd }}$ ed., pp. 125-151).

Tomlinson, C. (2005). Grading and Differentiation, Paradox or good Practice? Journal of Theory into practice, 44(3), 262- 269.

Pint rich, P. \& Zusho, A. (2002). Student Motivation and SelfRegulated Learning in the College Classroom, in. Smart, J. \&Tierney, W. (Eds.) .Higher Education: Handbook of Theory and Research, New York. Agathon Press. 